\title{
Psychosocial predictors of non-adherence to chronic medication: systematic review of longitudinal studies
}

This article was published in the following Dove Press journal:

Patient Preference and Adherence

25 April 2014

Number of times this article has been viewed

\author{
Hanneke E Zwikker ${ }^{1}$ \\ Bart J van den Bemt ${ }^{1,2}$ \\ Johanna E Vriezekolk' \\ Cornelia $\mathrm{H}$ van den Ende' \\ Sandra van Dulmen ${ }^{3-5}$ \\ 'Departments of Rheumatology \\ and Pharmacy, ${ }^{2}$ Department of \\ Pharmacy, Radboud University \\ Medical Centre, ${ }^{3}$ Department of \\ Primary and Community Care, \\ Radboud University Medical Centre, \\ Nijmegen, ${ }^{4}$ Netherlands Institute \\ for Health Services Research, the \\ Netherlands; ${ }^{5}$ Department of Health \\ Science, Buskerud University College, \\ Drammen, Norway
}

Correspondence: Bart van den Bemt Departments of Rheumatology and Pharmacy, Sint Maartenskliniek, PO Box 90II, 6500 GM Nijmegen, the Netherlands

Tel +3I 2436582 I3

Email b.vandenbemt@maartenskliniek.nl
Objectives: Several cross-sectional studies suggest that psychosocial factors are associated with non-adherence to chronic preventive maintenance medication (CPMM); however, results from longitudinal associations have not yet been systematically summarized. Therefore, the objective of this study was to systematically synthesize evidence of longitudinal associations between psychosocial predictors and CPMM non-adherence.

Materials and methods: PUBMED, EMBASE, CINAHL, and PsychINFO databases were searched for studies meeting our inclusion criteria. The reference lists and the ISI Web of Knowledge of the included studies were checked. Studies were included if they had an English abstract, involved adult populations using CPMM living in Western countries, and if they investigated associations between psychosocial predictors and medication non-adherence using longitudinal designs. Data were extracted according to a literature-based extraction form. Study quality was independently judged by two researchers using a framework comprising six bias domains. Studies were considered to be of high quality if $\geq$ four domains were free of bias. Psychosocial predictors for non-adherence were categorized into five pre-defined categories: beliefs/cognitions; coping styles; social influences and social support; personality traits; and psychosocial well-being. A qualitative best evidence synthesis was performed to synthesize evidence of longitudinal associations between psychosocial predictors and CPMM non-adherence.

Results: Of 4,732 initially-identified studies, 30 (low-quality) studies were included in the systematic review. The qualitative best evidence synthesis demonstrated limited evidence for absence of a longitudinal association between CPMM non-adherence and the psychosocial categories. The strength of evidence for the review's findings is limited by the low quality of included studies.

Conclusion: The results do not provide psychosocial targets for the development of new interventions in clinical practice. This review clearly demonstrates the need for high-quality, longitudinal research to identify psychosocial predictors of medication non-adherence.

Keywords: medication adherence, psychosocial factors, systematic review, longitudinal studies, somatic and chronic diseases

\section{Introduction}

In conditions such as rheumatoid arthritis, diabetes, and hypertension, long-term therapy with chronic preventive maintenance medication (CPMM) is essential for reducing risks of disease progression, comorbidity, and mortality. However, sufficient medication adherence to CPMM is a prerequisite for reducing these risks. ${ }^{1}$

Medication non-adherence, or the extent to which patients do not take their medications as agreed with their health care provider, averages $50 \%$ among patients suffering from chronic diseases in developed countries. ${ }^{2}$ Non-adherence can result in poorer 
health outcomes and a lower quality of life in patients. ${ }^{3}$ For example, patients who did not adhere to beta-blocker therapy were four and a half times more likely to have complications from coronary heart disease than those who adhered to therapy. ${ }^{4}$ Non-adherence also affects health care utilization. For instance, poorer adherence among elderly patients with moderate-to-severe asthma was associated with a 5\% increase in annual physician visits, whereas better adherence was associated with a $20 \%$ decrease in annual hospitalization. ${ }^{5}$

Considering the undesired consequences of non-adherence to CPMM, interventions are needed to improve medication non-adherence. According to the World Health Organization (WHO), possible targets for these interventions can be divided into five domains: ${ }^{2}$ socio-economic factors, health care system factors, condition-related factors, therapy-related factors, and patient-related factors. Although none of the factors within these domains are consistently associated with nonadherence across conditions, some tend to be better predictors of non-adherence than others (like poverty, the nature of the disease, and side-effects). ${ }^{1,2}$ Also, psychosocial factors like beliefs about medication, self-efficacy, and social support can be promising intervention targets. These are mostly modifiable (in contrast to factors like poverty or side-effects), and according to reviews of cross-sectional studies, they appear to be associated with non-adherence in various somatic, chronic conditions. ${ }^{6-13}$ Beliefs about medication were the most powerful predictors of adherence (among demographic and medical factors) in one cross-sectional study, ${ }^{9}$ while another cross-sectional study identified low-self-efficacy as a significant predictor of non-adherence across different countries, for example. ${ }^{11}$ However, there is no insight into psychosocial factors predicting non-adherence in longitudinal studies with a longer follow-up period ( $\geq 3$ months). Such knowledge would be helpful in designing effective adherence interventions in clinical practice.

This is the first review which aims to systematically synthesize evidence of longitudinal associations between psychosocial predictors and CPMM non-adherence across adult patients living in Western countries. Since non-adherence literature is scattered across diseases, ${ }^{14}$ we combined studies from various somatic, chronic conditions to increase the robustness of our findings.

\section{Methods}

PRISMA-guidelines were followed in performing this systematic review. ${ }^{15}$ The steps taken regarding data searches, study selection, data extraction, study quality assessment, data synthesis, and data analyses are elaborated below.

\section{Data sources and searches}

In March 2011, according to a pre-defined search strategy, four electronic databases (PUBMED, EMBASE, CINAHL, and PsychINFO) were searched for studies up to February 2011. With this search, a first set of studies was included, the reference lists of these studies were hand searched to find additional studies. The studies were also entered into the ISI Web of Knowledge citation index (August 2011). The resulting list of studies, citing one of the initial included studies in our review, was also searched.

The search strategy (see Supplementary Materials) contains key words on medication adherence, chronic, somatic diseases, adults, longitudinal designs, and Western countries. Countries in Africa, Latin-America, SouthAmerica, Asia (excluding Indonesia and Japan), and Turkey were considered as non-Western according to Statistics Netherlands. ${ }^{16}$ Non-Western countries were excluded because underlying mechanisms of medication non-adherence could differ from those in Western countries due to socio-economic and cultural differences. ${ }^{17}$

In this review, we focused on two of the three components of adherence (ie, on initiation and implementation adherence, thus the extent to which a patient's actual medication dosing regimen corresponds with the prescribed dosing regimen from initiation to last dose). We did not include discontinuation of medication. ${ }^{1}$

As using CPMM terms in the search strategy was unfeasible, we used the corresponding diseases for which the CPMMs were prescribed as search terms instead. The disease terms were selected as follows:

1. Chronic preventive maintenance medications were defined. CPMMs were regarded as drugs that 1) are intended to be used chronically to prevent the occurrence or worsening of a disease or its complications; and 2) may have an immediate effect, but must also have a long-term effect ( $>3$ months).

2. From the full November 2010 Anatomical Therapeutic Chemical Classification System (ATC)-7 medication list of drugs available in the Netherlands, 246 CPMMs (Supplementary Materials) were independently selected by two pharmacists (BvdB and $\mathrm{VH})$. There was an initial agreement of $96 \%$ on medications being CPMM. Disagreements were resolved by discussion between the pharmacists.

3. Disease indications for the 246 CPMMs were subsequently clustered by BvdB according to the International Classification of Diseases (WHO). Finally, 20 disease terms were used in the search strategy. 


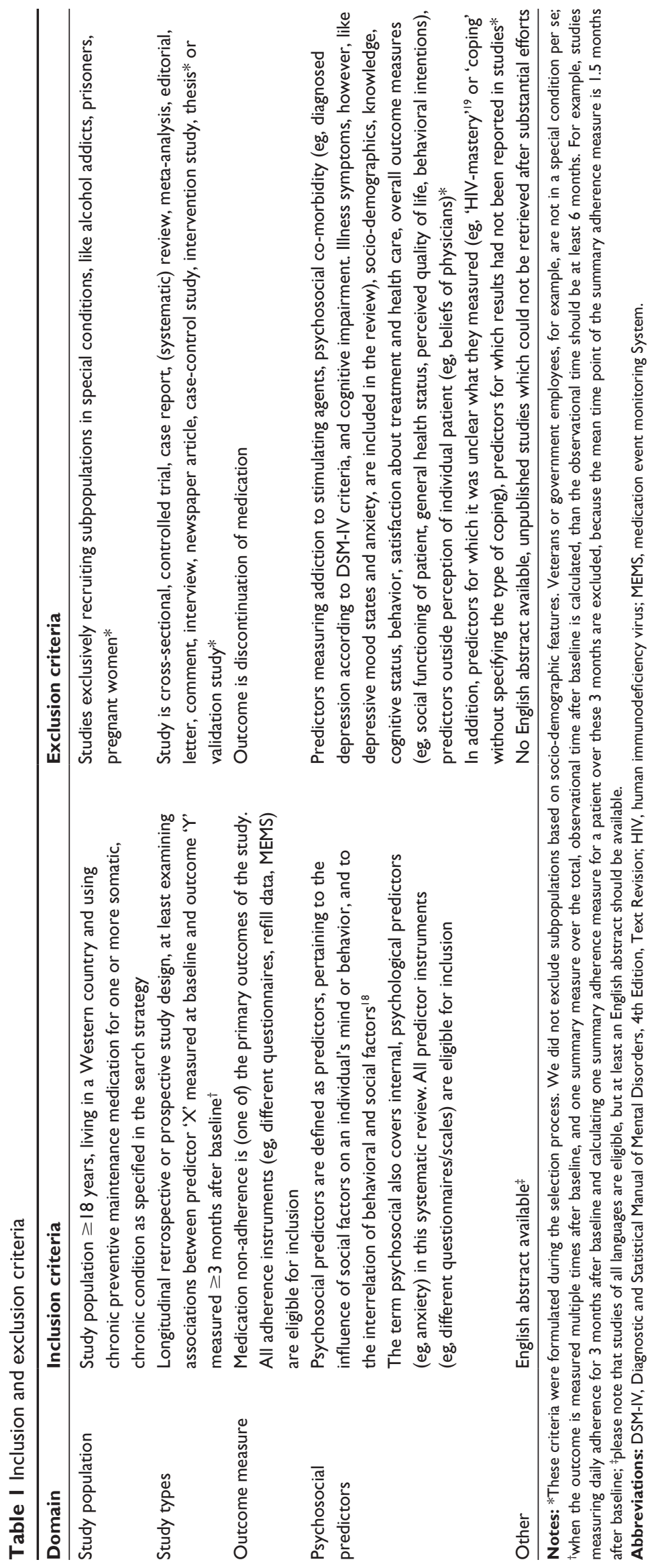


Table 2 Study characteristics and results*

\begin{tabular}{|c|c|c|c|c|}
\hline \multirow[t]{2}{*}{ First author } & \multirow[t]{2}{*}{ Setting } & \multicolumn{3}{|c|}{ Sample characteristics } \\
\hline & & $\begin{array}{l}\text { Sample size, } \\
\text { \% loss to follow-up }\end{array}$ & Age $^{\dagger}, \%$ female & Disease duration $^{\dagger}$ \\
\hline \multicolumn{5}{|c|}{ Asthma (inhaled corticosteroids) } \\
\hline Ponieman ${ }^{33}$ & $\begin{array}{l}\text { USA; patients from general } \\
\text { internal medicine clinic }\end{array}$ & $261,23 \%$ & $48(13), 82 \%$ & $\begin{array}{l}\text { Age of onset } \leq 20 \\
\text { years: } 50 \% \text { of sample }\end{array}$ \\
\hline \multicolumn{5}{|c|}{ Diabetes (oral and/or parenteral antidiabetics) } \\
\hline Venturini ${ }^{34, \dagger \dagger}$ & $\begin{array}{l}\text { USA; patients from HMO- } \\
\text { providing health services }\end{array}$ & $786,0 \%$ & 59 (mean), 24-92 (range), 49\% & NR \\
\hline \multicolumn{5}{|c|}{ Heart disease and hypertension (cardiovascular medication) } \\
\hline Gazmararian $^{35}$ & $\begin{array}{l}\text { USA; community-dwelling } \\
\text { patients }{ }^{\ddagger}\end{array}$ & I,549, UD & $\begin{array}{l}\text { Age: } 65-69: 35 \%, 70-74: 28 \% \\
75-79: 20 \%, 80-84: 12 \%,>84: \\
6 \% \text {, (female): } 58 \%\end{array}$ & UD \\
\hline $\mathrm{Nabi}^{26}$ & $\begin{array}{l}\text { Finland; local government } \\
\text { employees }\end{array}$ & I,02I, UD & $26-63$ (range), $32 \%$ & $\begin{array}{l}0-2 \text { years: } n=311 \\
2-5 \text { years: } n=222 \\
\text { 5- } 10 \text { years: } n=292 \\
>10 \text { years: } n=196\end{array}$ \\
\hline Grégoire ${ }^{36}$ & $\begin{array}{l}\text { Canada; hypertensive adults with } \\
\text { prescriptions from network } \\
\text { of pharmacies }\end{array}$ & $692,26 \%$ & $59(13), 56 \%$ & $\begin{array}{l}47 \text { months } \\
\text { (adherent group), } \\
44 \text { months (non- } \\
\text { adherent group) }\end{array}$ \\
\hline Miller ${ }^{37}$ & $\begin{array}{l}\text { Site not reported: patients from } \\
\text { institutions providing cardiac } \\
\text { rehabilitation programs }{ }^{\text {Tा }}\end{array}$ & $|4|, 21 \%$ & 56 (mean), 32-70 (range), 22\% & NR \\
\hline Molloy ${ }^{38}$ & $\begin{array}{l}\text { UK; patients admitted to hospitals } \\
\text { with acute coronary syndrome }\end{array}$ & $295,11 \%$ & 61 (mean), 32-87 (range), 23\% & 0 years (acute) \\
\hline \multicolumn{5}{|c|}{ HIV (antiretroviral medication) } \\
\hline Deschamps ${ }^{25}$ & $\begin{array}{l}\text { Belgium; outpatients at university } \\
\text { hospital }\end{array}$ & $60,28 \%$ & $\begin{array}{l}43 \text { (9) adherent group, } \\
41 \text { (8) non-adherent group, 16\% }\end{array}$ & NR \\
\hline Holmes ${ }^{19}$ & USA; HIV-clinic patients & $116,0 \% \S$ & $\begin{array}{l}44 \text { (median), } \\
25-69 \text { (range), 19\% }\end{array}$ & 5 years (median) \\
\hline Delgado 39 & $\begin{array}{l}\text { Canada; patients enrolled } \\
\text { in community drug treatment } \\
\text { program }\end{array}$ & $316,0 \%$ & NR, NR & NR \\
\hline Singh ${ }^{40}$ & $\begin{array}{l}\text { USA; new, veteran patients seen } \\
\text { at medical center }\end{array}$ & $52,12 \%$ & $\begin{array}{l}40 \text { (median), } \\
23-68 \text { (range), 0\% }\end{array}$ & NR \\
\hline Singh ${ }^{41}$ & $\begin{array}{l}\text { Site not reported: patients } \\
\text { in HIV-medical centers }\end{array}$ & $138,11 \%$ & $\begin{array}{l}\text { 4I (median), } \\
24-7 \mid \text { (range), } 7 \%\end{array}$ & $\begin{array}{l}\text { NR (but } 7 \% \\
\text { therapy-naive) }\end{array}$ \\
\hline Bottonari ${ }^{42}$ & $\begin{array}{l}\text { USA; patients treated in } \\
\text { immunodeficiency clinic }\end{array}$ & $78,69 \%$ & $36(7), 4 \%$ & NR \\
\hline Godin $^{43}$ & $\begin{array}{l}\text { Canada; patients from medical } \\
\text { HIV-clinics }\end{array}$ & $400,6 \%$ & $43(8), 4 \%$ & $\begin{array}{l}>5 \text { years HIV- } \\
\text { infected: } 73 \%\end{array}$ \\
\hline
\end{tabular}




\begin{tabular}{|c|c|c|c|}
\hline \multicolumn{4}{|l|}{ Measures and results } \\
\hline Adherence $^{\ddagger}$, follow-up period ${ }^{\S}$ & $\begin{array}{l}\text { Psychosocial category, } \\
\text { number of predictors"l }\end{array}$ & $\begin{array}{l}\text { Association present between category } \\
\text { and adherence/non-adherence? }\end{array}$ & $\begin{array}{l}\text { Number domains } \\
\text { bias free** }\end{array}$ \\
\hline \multirow[t]{2}{*}{ Self-report (MARS), 3 months } & $\mathrm{Al}, \mathrm{n}=5$ & No (U: yes, M: no) & 0 of 6 \\
\hline & Alll, $n=3$ & No (U: no, M: no) & \\
\hline $\begin{array}{l}\text { Record review, last time point flexible, } \\
\text { but within } 24 \text { months }\end{array}$ & $\mathrm{El}, \mathrm{n}=\mathrm{I}$ & No (U: NR, M: no) & 2 of 6 \\
\hline Record review, 12 months & CIII, $n=I$ & No (U: no, M: NT) & 3 of 6 \\
\hline \multirow[t]{2}{*}{ Record review, 12 months } & $D, n=4$ & Yes (U: no, M: yes) & I of 6 \\
\hline & $\mathrm{El}, \mathrm{n}=2$ & No (U: no, M: NT) & \\
\hline \multirow[t]{3}{*}{ Self-report (Morisky scale), 3 months } & Al, $n=I$ & No (U: no, M: no) & 0 of 6 \\
\hline & All, $n=5$ & No (U: no, M: no) & \\
\hline & CIII, $n=I$ & No (U: no, M: no) & \\
\hline \multirow[t]{2}{*}{ Self-report (HBS), 6-9 months } & $\mathrm{Al}, \mathrm{n}=\mathrm{I}$ & No (U: NR, M: no) & 0 of 6 \\
\hline & CII, $n=I$ & No (U: NR, M: no) & \\
\hline Self-report, 12 months & CIII, $n=2$ & No (U: no, M: no) & 1 of 6 \\
\hline MEMS, 5-6 months after measuring & $\mathrm{Al}, \mathrm{n}=3$ & No (U: no, M: NR) & I of 6 \\
\hline \multirow[t]{6}{*}{ psychosocial constructs } & Alll, $n=I$ & No (U: no, M: NR) & \\
\hline & $\mathrm{BI}, \mathrm{n}=3$ & No (U: no, M: NR) & \\
\hline & BII, $n=4$ & No (U: no, M: NR) & \\
\hline & CIII, $n=2$ & No (U: no, M: NR) & \\
\hline & $D, n=I$ & No (U: no, M: NR) & \\
\hline & $\mathrm{El}, \mathrm{n}=2$ & No (U: no, M: NR) & \\
\hline \multirow{6}{*}{$\begin{array}{l}\text { MEMS, I } 2 \text { months (or when viral load } \\
\text { of } \geq 1,000 \text { copies } / \mathrm{mL} \text { was reached) }\end{array}$} & $\mathrm{Al}, \mathrm{n}=\mathrm{I}$ & No (U: no, M: no) & 2 of 6 \\
\hline & All, $n=2$ & No (U: no, M: no) & \\
\hline & $\mathrm{Cl}, \mathrm{n}=\mathrm{I}$ & No (U: no, M: NT) & \\
\hline & CIII, $n=I$ & No (U: no, M: NT) & \\
\hline & El, $n=I$ & No (U: no, M: no) & \\
\hline & Ell, $n=I$ & No (U: no, M: no) & \\
\hline Record review, 12 months & El, $n=I$ & No (U: yes, M: no) & 1 of 6 \\
\hline \multirow[t]{3}{*}{ Record review, 6 months } & BII, $n=I$ & No (U: no, M: no) & I of 6 \\
\hline & CIII, $n=2$ & No (U: no, M: no) & \\
\hline & El, $n=4$ & No (U: no, M: no) & \\
\hline \multirow[t]{4}{*}{ Record review, 6 months } & $\mathrm{BI}, \mathrm{n}=3$ & No (U: no, M: NR) & I of 6 \\
\hline & BII, $n=6$ & No (U: no, M: NR) & \\
\hline & CIII, $n=4$ & No (U: no, M: NR) & \\
\hline & El, $n=I$ & No (U: no, M: NR) & \\
\hline \multirow[t]{3}{*}{ Self-report (straightforward), 6-9 months } & $D, n=2$ & No (U: no, M: NR) & 0 of 6 \\
\hline & $\mathrm{El}, \mathrm{n}=\mathrm{I}$ & No: (U: no, M: NR) & \\
\hline & Ell, $n=3$ & No: (U: no, M: NR) & \\
\hline \multirow[t]{5}{*}{ Self-report (straightforward), 12 months } & $\mathrm{Al}, \mathrm{n}=\mathrm{I}$ & Yes (U: NR, M: yes) & I of 6 \\
\hline & Alll, $n=2$ & No (U: NR, M: no) & \\
\hline & $\mathrm{Cl}, \mathrm{n}=\mathrm{I}$ & No (U: NR, M: no) & \\
\hline & CIII, $n=I$ & No (U: NR, M: no) & \\
\hline & $\mathrm{D}, \mathrm{n}=\mathrm{I}$ & No (U: NR, M: no) & \\
\hline
\end{tabular}


Table 2 (Continued)

\begin{tabular}{|c|c|c|c|c|}
\hline \multirow[t]{2}{*}{ First author } & \multirow[t]{2}{*}{ Setting } & \multicolumn{3}{|c|}{ Sample characteristics } \\
\hline & & $\begin{array}{l}\text { Sample size, } \\
\% \text { loss to follow-up }\end{array}$ & Age $^{\dagger}, \%$ female & Disease duration $^{\dagger}$ \\
\hline Kacanek $^{44}$ & $\begin{array}{l}\text { USA; patients recruited by } \\
\text { media and physician networks }\end{array}$ & $225,0 \%$ & 45 (7), $23 \%$ & NR \\
\hline Martini ${ }^{45}$ & $\begin{array}{l}\text { Italy; outpatients using } \\
\text { combination therapy }\end{array}$ & $214,71 \%$ & $\begin{array}{l}<30: \text { I3\%, 30-39: } 56 \% \\
>39: 31 \% \text {, (female): } 36 \%\end{array}$ & NR \\
\hline Mellins $^{46}$ & $\begin{array}{l}\text { USA; HIV-infected mothers } \\
\text { recruited in waiting room } \\
\text { of adult clinic }\end{array}$ & $128,25 \%$ & $\begin{array}{l}38 \text { (mean), } \\
22-66 \text { (range), 100\% }\end{array}$ & 5 years \\
\hline Nilsson Schönnesson ${ }^{47}$ & $\begin{array}{l}\text { Sweden; patients recruited } \\
\text { by clinic nurses }\end{array}$ & $203,29 \%$ & 45 (9), 22\% & $\begin{array}{l}\text { Mean year of } \\
\text { diagnosis }=1990\end{array}$ \\
\hline Thrasher $^{48}$ & $\begin{array}{l}\text { USA; patients in public use } \\
\text { of HCSUS data set }\end{array}$ & $\mathrm{I}, 91 \mathrm{I}, 33 \% \S$ & $\begin{array}{l}\text { Minority versus non-minority: } \\
<35: 35 \% \text { minority group, } 30 \% \\
\text { non-minority group. } \% \text { female: } \\
33 \% \text { versus } 12 \% \text {, respectively }\end{array}$ & $\begin{array}{l}\text { Mean year first } \\
\text { diagnosed with } \\
\text { HIV: 1992, minority } \\
\text { group; 1990, } \\
\text { non-minority group }\end{array}$ \\
\hline Horne $^{49}$ & $\begin{array}{l}\text { UK; outpatients, eligible } \\
\text { to receive HAART }\end{array}$ & $136,14 \%$ & 38 (9), NR & 5 years \\
\hline Mugavero 50 & $\begin{array}{l}\text { USA; patients receiving care } \\
\text { at infectious disease clinics }\end{array}$ & $474,39 \%$ & $\begin{array}{l}40 \text { (median), } \\
35-46 \text { (IQR), 29\% }\end{array}$ & NR \\
\hline Carrieri $^{51}$ & $\begin{array}{l}\text { France; patients starting } \\
\text { HAART-regimen }\end{array}$ & $1,110,13 \%$ & 37 (median), 22\% & $\begin{array}{l}\text { First time since first } \\
\text { positive HIV-test in } \\
\text { years: } 3.8 \text { (median), } \\
0.5-8.2 \text { (IQR) }\end{array}$ \\
\hline \multicolumn{5}{|c|}{ Transplant-related (immunosuppressant medication) } \\
\hline Stilley ${ }^{52}$ & $\begin{array}{l}\text { USA; transplant patients, } \\
\text { recruited before hospital } \\
\text { discharge or at early clinic visit }\end{array}$ & $152,29 \%$ & 55 (10), 33\% & NR \\
\hline De Geest ${ }^{53}$ & $\begin{array}{l}\text { Belgium; convenience sample } \\
\text { of outpatients }\end{array}$ & $101,0 \%$ & $\begin{array}{l}56 \text { (median), } \\
\text { 20-69 (range), 13\% }\end{array}$ & $\begin{array}{l}3 \text { (median), } 1-6 \\
\text { (range) years since } \\
\text { transplantation }\end{array}$ \\
\hline Russell $^{54}$ & $\begin{array}{l}\text { USA; convenience sample } \\
\text { of renal transplant patients }\end{array}$ & $50,26 \%$ & $60(5), 38 \%$ & NR \\
\hline Weng ${ }^{55}$ & $\begin{array}{l}\text { USA; patients recruited at time } \\
\text { of renal transplantation }\end{array}$ & $829,66 \%$ & $\begin{array}{l}48 \text { (median), } \\
\text { 39-57 (IQR), 39\% }\end{array}$ & NR \\
\hline $\operatorname{Dew}^{56}$ & $\begin{array}{l}\text { USA; heart transplant patients } \\
\text { from academic hospitall II }\end{array}$ & $108,22 \%$ & $<50$ years: $49 \%$, (female): $16 \%$ & NR \\
\hline Dew $^{57}$ & $\begin{array}{l}\text { USA; patients receiving first } \\
\text { lung transplantation in academic } \\
\text { hospital }\end{array}$ & $178,29 \%$ & $37 \%<50$ years, (female): $48 \%$ & NR \\
\hline
\end{tabular}




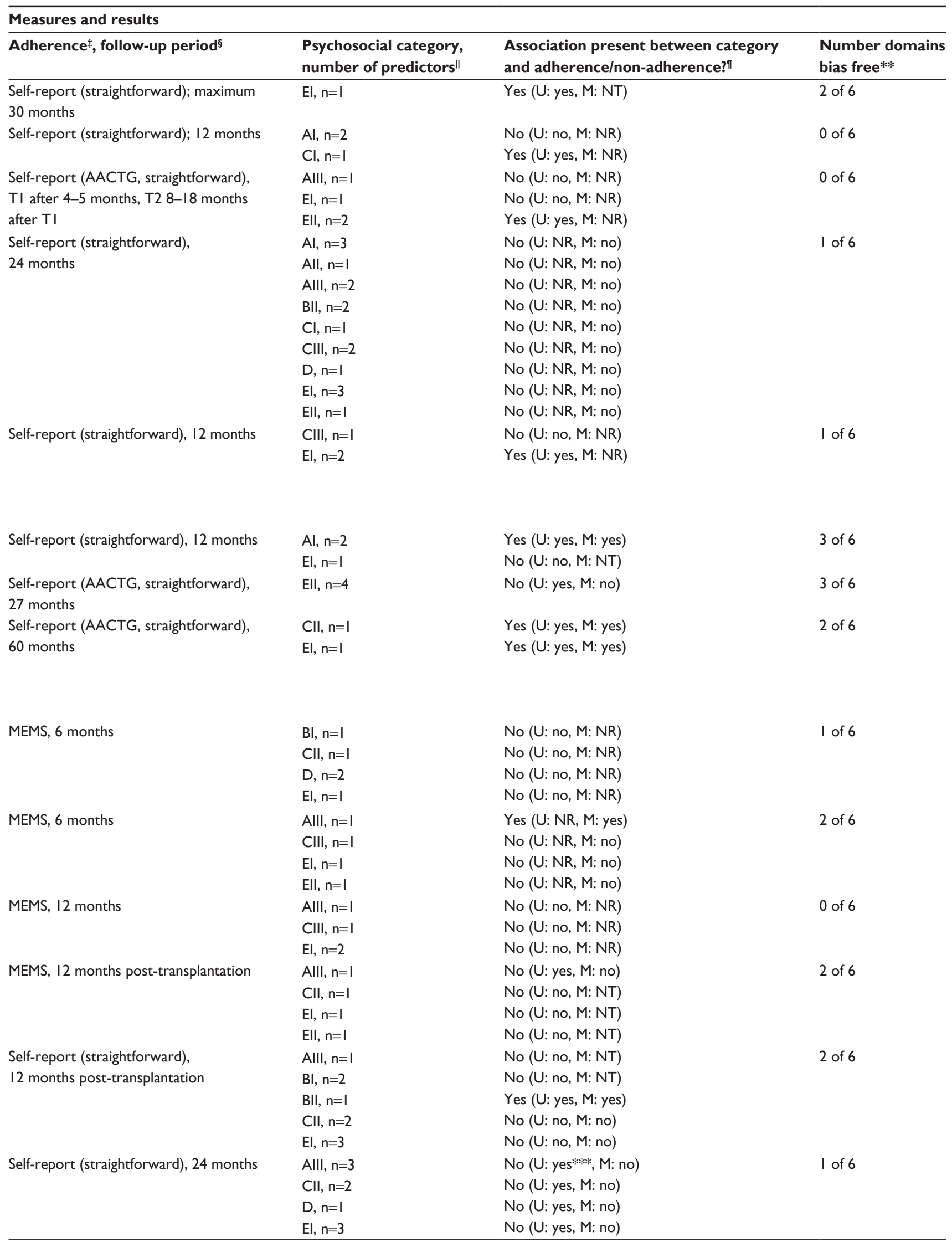


Table 2 (Continued)

\begin{tabular}{|c|c|c|c|c|}
\hline \multirow[t]{2}{*}{ First author } & \multirow[t]{2}{*}{ Setting } & \multicolumn{3}{|c|}{ Sample characteristics } \\
\hline & & $\begin{array}{l}\text { Sample size, } \\
\% \text { loss to follow-up }\end{array}$ & Age $^{\dagger}, \%$ female & Disease duration ${ }^{\dagger}$ \\
\hline Dobbels ${ }^{58}$ & $\begin{array}{l}\text { Belgium; heart, liver and lung } \\
\text { transplant patients listed at } \\
\text { university hospitals }\end{array}$ & $186,24 \%$ & 52 (I2), 33\% & NR \\
\hline \multicolumn{5}{|c|}{ Other (diabetes and/or hypertension and/or heart disease) } \\
\hline DiMatteo $^{59}$ & $\begin{array}{l}\text { USA; patients from five medical } \\
\text { specialties in HMOs, large } \\
\text { multispecialty groups or solo } \\
\text { practices } \neq \neq, \text { ITा }\end{array}$ & Max I,828, UD & $60(8), 54 \%$ & NR \\
\hline
\end{tabular}

Notes: *NS (non significant): as reported in the concerning study. UD (undetermined): because of inadequate description in the concerning study; ${ }^{\dagger}$ mean (and for age: standard deviation) in years reported unless indicated otherwise; ‘with straightforward, we mean that participants were directly asked to indicate how many medication doses they missed. For example: "How many pills did you take this week?"; sfollow-up period = number of months between baseline (unless indicated otherwise) and last adherence measurement; "this column shows the number of psychosocial predictors measured in the concerning study, and the assigned psychosocial category. Details about the single predictors are presented in Table S2. A = Beliefs and cognitions about I) medication and treatment; II) illness; III) self-efficacy and locus of control. B = coping styles I) task oriented, II) emotion oriented. C = Social influences and social support I) regarding medical caregiver; II) regarding friends and family; III) in general. D = personality traits. $\mathrm{E}=$ psychological well-being: I) mood state; II) perceived stress/stressors; "no = no significant association between psychosocial category and medication adherence/nonadherence within study when $P \leq 0.05$; Yes = significant association when $P \leq 0.05$; $U$ : univariate; $M$ : multivariate; **to determine methodological quality, six bias domains per study were judged. Here, the total amount of bias free domains is reported (for further details, see Table S3); ${ }^{\dagger}$ retrospective design; ${ }^{\ddagger \neq}$ diagnosis for coronary heart disease, hypertension, diabetes mellitus, and/or hyperlipidemia; ${ }^{\$} \%$ loss to follow-up assumed by HZ/BvdB; $\|$ lltype of medication is immunosuppressants, antihypertensives, and/or antivirals; Tा"use of chronic preventive medication assumed; ***significance of $P \leq 0.05$ assumed by $\mathrm{HZ} / \mathrm{BvdB}$.

Abbreviations: AACTG, adult AIDS clinical trials group; HAART, highly active antiretroviral therapy; HBS, health behavior scale; HCSUS, HIV cost and services utilization study; HIV, human immunodeficiency virus; HMO, health maintenance organization; IQR, interquartile range; MARS, medication adherence report scale; MEMS, medication event monitoring system; NR, not reported; NS, non significant; NT, not tested; UD, undetermined.

\section{Study selection}

Studies were selected based on the criteria in Table 1.

Studies exclusively recruiting subpopulations in special conditions (like prisoners, pregnant women) were excluded. Their results only pertain to a specific group of patients, therefore, including them might have introduced bias into this systematic review.

Two reviewers (BvdB and HZ) independently assessed studies for eligibility in two phases: 1) screening based on title and abstract; and 2) screening based on full text. Disagreements between BvdB and $\mathrm{HZ}$ were resolved by discussion; a third reviewer (CvdE) made decisions in case disagreements could not be resolved. Studies in Spanish or Portuguese were judged by LvdA. During the study selection process, three authors were contacted about statistics, outcome measure, or study design to determine eligibility for this review. ${ }^{20-22}$

\section{Data extraction and quality assessment}

For data extraction, a literature-based, standard form was developed. ${ }^{23,24}$ Information regarding study setting, design, descriptive statistics, measures, and analysis were extracted by HZ; BvdB arbitrarily selected $15 \%$ of the included studies to check appropriateness of all extracted data of these studies, and also checked all doubts indicated on the form by HZ.

If multiple adherence measures were presented in one study (eg, about dosing, timing, or taking medication) $)^{25}$, we only extracted data about taking medication. Two authors were contacted during the extraction process to check the duration of a follow-up period of $\geq 3$ months ${ }^{26}$ or to explain ambiguities. ${ }^{19}$

We adapted the framework developed by Hayden et a ${ }^{27}$ to judge methodologic study quality. Our framework contained 23 items divided into six bias domains: study participation, study attrition, prognostic, outcome and confounding measurement, and analyses. Each item was scored as 'yes' (no unacceptable amount of bias introduced), 'partly' (/unsure), and 'no' (unacceptable amount of bias introduced). For every bias domain, a transparent method was used to reach overall judgment about the presence or absence of bias (see Table S1). Studies with $\geq$ four domains judged as 'yes' were considered high-quality studies; studies with $<$ four domains were considered low-quality studies.

Using three randomly selected studies not included in the review, the framework was piloted by $\mathrm{BvdB}$ and $\mathrm{HZ}$, who also performed the actual quality assessment. Disagreements were resolved by discussion and, when necessary, a third reviewer (CvdE) made final decisions. On the domain level, a weighted extent of agreement between $\mathrm{BvdB}$ and $\mathrm{HZ}$ (quadratic weighting scheme) was calculated due to the ordinal nature of the scores. ${ }^{28,29}$

\section{Data synthesis and analysis}

Because over 70 non-identical psychosocial predictors (nonidentical by name and/or measurement instrument) were studied in this review, and because of the variety of instruments used to measure non-adherence, a qualitative instead 


\begin{tabular}{|c|c|c|c|}
\hline \multicolumn{4}{|l|}{ Measures and results } \\
\hline Adherence $^{\ddagger}$, follow-up period ${ }^{\S}$ & $\begin{array}{l}\text { Psychosocial category, } \\
\text { number of predictors" }\end{array}$ & $\begin{array}{l}\text { Association present between category } \\
\text { and adherence/non-adherence?" }\end{array}$ & $\begin{array}{l}\text { Number domains } \\
\text { bias free** }\end{array}$ \\
\hline Self-report (straightforward), 12 months & CIII, $n=2$ & No (U: NR, M: no) & I of 6 \\
\hline \multirow[t]{2}{*}{ post-transplantation } & $D, n=5$ & No (U: NR, M: no) & \\
\hline & $\mathrm{El}, \mathrm{n}=2$ & No (U: NR, M: no) & \\
\hline \multirow[t]{4}{*}{ Self-report (straightforward), 24 months } & BII, $n=I$ & No (U: NR, M: no) & 0 of 6 \\
\hline & $\mathrm{Cl}, \mathrm{n}=2$ & No (U: NR, M: no) & \\
\hline & CIII, $n=I$ & No (U: NR, M: no) & \\
\hline & Ell, $n=I$ & Yes (U: NR, M: yes) & \\
\hline
\end{tabular}

of a quantitative analysis was considered to be appropriate. ${ }^{30}$ Therefore, the results regarding associations between psychosocial predictors and medication non-adherence were qualitatively synthesized in four steps.

In step 1, psychosocial categories were formulated. Initially, all psychosocial elements as mentioned in general health behavior models and theories ${ }^{31,32}$ were listed (HZ). Subsequently, based on consensus, the elements were clustered by $\mathrm{HZ}$ and three psychologists (SvD, JV, and LK) resulting in the categories of Figure 1.

Next, the psychosocial predictors within the studies of the review were assigned to one of the categories in Figure 1 (HZ and the psychologists). In this way, the considerable number of single, non-identical predictors was dealt with.

In step 2, for each psychosocial predictor within a category and within a study, the presence of a significant univariate and multivariate association with medication non-adherence was determined (see Table S2). Statistical significance was set at $P<0.05$.

In step 3, results within studies were synthesized per psychosocial category. When $\geq 75 \%$ of variables within a single psychosocial category were significantly and consistently (ie, same predictors in same direction) associated with non-adherence, a 'yes' was assigned (ie, association present). When $\geq 75 \%$ of variables were significantly, but inconsistently, associated (eg, four of five predictors in category about depressive symptoms, of which two are positively related to non-adherence and two are negatively related), the term 'conflicting' was assigned. When $<75 \%$ of variables were significantly and consistently associated, a 'no' was assigned. Multivariate results were preferably used to synthesize results in this step. When multivariate results were not reported, univariate results were used.

In the fourth and final step, a best evidence synthesis (BES) per psychosocial category between studies was performed to summarize evidence of longitudinal associations between the predictors in the psychosocial

\begin{tabular}{|c|c|}
\hline \multirow[t]{4}{*}{ A. } & Beliefs and cognitions \\
\hline & I About medication and treatment \\
\hline & II About illness \\
\hline & III Regarding self-efficacy and locus of control \\
\hline \multirow[t]{3}{*}{ B . } & Coping styles \\
\hline & I Task-oriented \\
\hline & II Emotion-oriented \\
\hline \multirow[t]{4}{*}{ C. } & Social influences and social support \\
\hline & I Regarding medical caregiver \\
\hline & II Regarding friends and family \\
\hline & III In general \\
\hline D. & Personality traits \\
\hline E. & Psychosocial well-being \\
\hline & I Mood state \\
\hline & II Perceived stress(ors) \\
\hline
\end{tabular}

Figure I Psychosocial categories. 
categories and medication non-adherence. We defined four levels of evidence as used in previous reviews of longitudinal studies: ${ }^{60-62}$

1. Strong evidence: consistent findings ( $\geq 75 \%$ of studies within psychosocial category report same conclusion about association; ie, 'yes, present' or 'no, not present') in at least two high-quality studies.

2. Moderate evidence: consistent findings in one highquality study AND at least two low-quality studies.

3. Limited evidence: findings in one high-quality study OR consistent findings in at least two low-quality studies.

4. Conflicting evidence: inconsistent findings in at least two studies irrespective of study quality (ie, $<75 \%$ of studies report same conclusion about association). Note that this level of evidence was checked first before assigning strong, moderate or limited evidence level to a category.

The level of evidence was undeterminable when $\leq$ one study of low quality was available for a psychosocial category.

Sensitivity analyses were performed to examine the robustness of findings, regarding the cut-off point for methodological quality, diseases, adherence measurement, and statistical analyses (ie, focusing on univariate analyses only). Also, an additional analysis on single predictors was carried out, since associations between single predictors like 'avoidance coping' and non-adherence could be overshadowed by combining them into a single category with generally non-significant psychosocial predictors, such as hopelessness and confusion. Three steps were taken: 1) all significant predictors ( $P \leq 0.05$ ) were listed; 2 ) each of these predictors was grouped with identically named, significant and non-significant predictors; and 3) when at least two studies were available for those predictors, the BES rules were applied.

\section{Results}

\section{Study inclusion}

Of 4,732 non-duplicate references, 30 met our inclusion criteria (Figure 2). ${ }^{19,25,26,33-59}$ In all, 1,255 records were identified by screening the reference lists and the ISI Web of Knowledge citation index of the initial included studies.

Initially, the percentage of agreement regarding the eligibility of studies was $86 \%$ (of the 272 studies selected on title and abstract, agreement was obtained in about 235 studies after reading the full-text). Disagreements were mainly due to misconceptions about psychosocial predictors (eg, clinically diagnosed depression versus symptoms of depression), study design, and adherence measure (ie, discontinuation or execution adherence). For one study, ${ }^{52}$ disagreement could not be resolved by discussion and thus a final decision was made by CvdE.

\section{Study characteristics and quality assessment}

Table 2 displays study characteristics, measures, and results. A comprehensive table of measures and results is presented in Table S2.

The included studies (all based on different data sets) covered CPMMs for asthma, diabetes, heart diseases/hypertension, human immunodeficiency virus (HIV), and organ transplants. Medication type was not explicitly mentioned in four studies, ${ }^{37,38,45,59}$ but we assumed CPMM was used since CPMM is the standard medical treatment for the 20 selected diseases in this review. In most studies, patients were recruited from medical clinics or hospitals and the sample size ranged from $50-1,911$. Attrition rates varied from $0 \%-71 \%$. Participants were predominantly men and often $\geq 37$ years of age and a disease duration of $>2$ years. The observation period between baseline and last adherence measurement was $\geq 3$ and $<12$ months in ten studies and $\geq 12$ months in 20 studies, with a maximum of 60 months. Medication adherence was mostly measured by self-report (18 studies, predominantly questionnaires); seven studies used a validated adherence questionnaire. ${ }^{33,36,43,46,49-51}$ Other adherence measurements were carried out by reviewing medical records or the medication event monitoring system (MEMS). In 15 studies, both univariate and multivariate analyses were reported.

All 30 included studies were judged to be 'low-quality' (Table S3). This was mainly due to poor descriptions and/ or bias regarding the study sample, the use of non-validated questionnaires, the lack of accounting for confounding variables, and a poor description of the data analyses. Most studies, moreover, did not appropriately describe actions taken in case of missing data.

A total of 180 bias domains were judged (30 studies by six domains). Initially, BvdB and $\mathrm{HZ}$ fully agreed on 78 domains, partially agreed (ie, 'partly' versus 'no' or 'partly' versus 'yes') on 79 domains and fully disagreed (eg, 'yes' versus 'no') on 23 domains, resulting in a weighted agreement of $76 \%$. Disagreements were caused by poor description of methods, different interpretations of missing data, differences in calculating study attrition rates, and different interpretations regarding the appropriateness of study sample descriptions. On this latter point, disagreements about three studies ${ }^{35,48,52}$ could not be resolved by discussion between $\mathrm{BvdB}$ and $\mathrm{HZ}$ and, thus, CvdE made the final decision. 


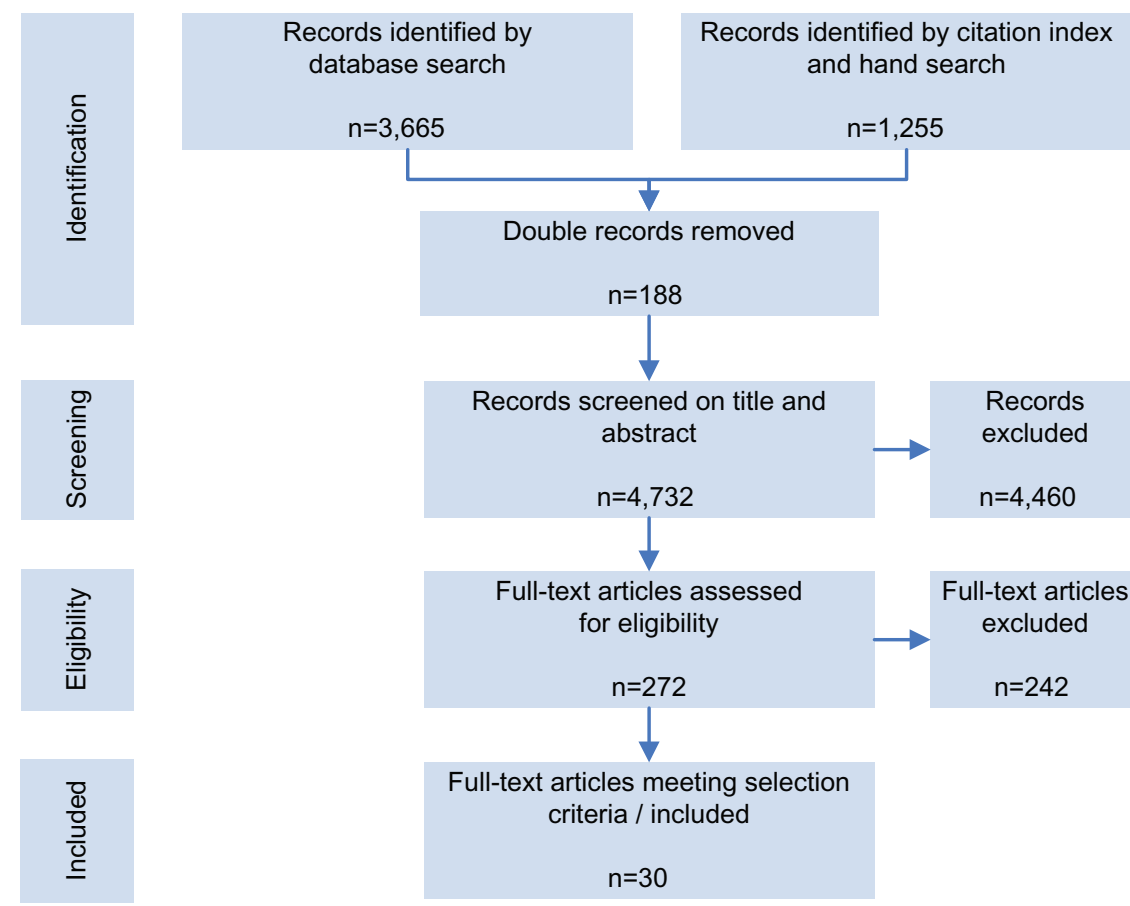

Figure 2 Flowchart of study inclusion process.
Abbreviation: CPMM, chronic preventive maintenance medication.

\section{Best evidence synthesis}

Table 3 shows there is limited evidence for the absence of a longitudinal association with medication non-adherence in all of the eleven psychosocial subcategories.

\section{Beliefs and cognitions}

Regarding category AI (beliefs and cognitions about medication and treatment), two of nine studies found a longitudinal, multivariate association between having a positive attitude towards taking medication and adherence (odds ratio $[\mathrm{OR}]=1.56,95 \%$ confidence interval $[\mathrm{CI}]$ $1.18,2.06),{ }^{43}$ and between necessity beliefs and concern beliefs about medication and adherence $(\mathrm{OR}=2.19,95 \%$ CI 1.02, 4.71 and OR $=0.45,95 \%$ CI 0.22, 0.96, respectively). ${ }^{49}$ One other study ${ }^{33}$ found univariate associations between necessity and concern beliefs about medication and adherence, but these associations did not hold in the multivariate analysis.

One study demonstrated a longitudinal, multivariate association between low self-efficacy and medication non-adherence, ${ }^{53}$ however, the effect size was small. Univariate, but not multivariate associations between self-efficacy and adherence were demonstrated in two studies. ${ }^{55,57}$

\section{Coping styles}

No univariate and multivariate associations were found between the task-oriented coping style category and medication adherence.

Regarding emotion-oriented coping styles, one of six studies revealed a multivariate association with non-adherence (eg, OR of 9.71 for avoidance coping) ${ }^{56}$ Furthermore, avoidance coping as a single predictor was associated with non-adherence in three of four studies measuring this construct. ${ }^{25,40,56}$

\section{Social influences and social support}

Two of the 25 studies demonstrated significant associations between predictors within the category social influences and social support and (non-)adherence, but only one of these studies reported on a multivariate association between having support from a partner and non-adherence (regression coefficient $=-0.15,95 \% \mathrm{CI}-0.25,-0.05) .{ }^{51}$ Receiving practical social support was associated with better adherence as a single predictor. $^{38,41}$ 
Table 3 Level of evidence for longitudinal associations between psychosocial categories and medication non-adherence

\begin{tabular}{|c|c|c|c|c|}
\hline Psychosocial category & $\mathbf{N}$ of studies & Quality & Longitudinal association & Level of evidence \\
\hline \multicolumn{5}{|l|}{ A. Beliefs and cognitions } \\
\hline $\begin{array}{l}\text { I. About medication } \\
\text { and treatment }\end{array}$ & 9 & All low & $\begin{array}{l}2 \times \text { yss }^{43,49} \\
7 \times \text { no }^{19,25,33,36,37,45,47}\end{array}$ & $\begin{array}{l}\text { No association } \\
\text { (limited evidence) }\end{array}$ \\
\hline II. About illness & 3 & All low & $3 \times \mathrm{no}^{19,36,47}$ & $\begin{array}{l}\text { No association } \\
\text { (limited evidence) }\end{array}$ \\
\hline III. Self-efficacy and locus of control & 10 & All low & $\begin{array}{l}I \times \operatorname{yes}^{53} \\
9 \times \mathrm{no}^{25,33,43,46,47,54-56,57}\end{array}$ & $\begin{array}{l}\text { No association } \\
\text { (limited evidence) }\end{array}$ \\
\hline \multicolumn{5}{|l|}{ B. Coping styles } \\
\hline I. Task-oriented & 4 & All low & $4 \times \mathrm{no}^{25,41,52,56}$ & $\begin{array}{l}\text { No association } \\
\text { (limited evidence) }\end{array}$ \\
\hline II. Emotion-oriented & 6 & All low & $\begin{array}{l}I \times \operatorname{yes}^{56} \\
5 \times \mathrm{no}^{25,40,41,47,59}\end{array}$ & $\begin{array}{l}\text { No association } \\
\text { (limited evidence) }\end{array}$ \\
\hline \multicolumn{5}{|l|}{ C. Social influences and social support } \\
\hline I. Regarding medical caregiver & 5 & All low & $\begin{array}{l}1 \times \text { yes }^{45} \\
4 \times \text { no }^{19,43,47,59}\end{array}$ & $\begin{array}{l}\text { No association } \\
\text { (limited evidence) }\end{array}$ \\
\hline II. Regarding friends and family & 6 & All low & $\begin{array}{l}1 \times y_{e s}{ }^{51} \\
5 \times \mathrm{no}^{37,52,55-57}\end{array}$ & $\begin{array}{l}\text { No association } \\
\text { (limited evidence) }\end{array}$ \\
\hline III. In general & 14 & All low & $14 \times \mathrm{no}^{19,25,35,36,38,40,41,43,47,48,53,54,58,59}$ & $\begin{array}{l}\text { No association } \\
\text { (limited evidence) }\end{array}$ \\
\hline D. Personality traits & 8 & All low & $\begin{array}{l}\text { I } \times \text { yes }^{26} \\
7 \times \mathrm{no}^{25,42,43,47,52,57,58}\end{array}$ & $\begin{array}{l}\text { No association } \\
\text { (limited evidence) }\end{array}$ \\
\hline \multicolumn{5}{|l|}{ E. Psychosocial well-being } \\
\hline I. Mood state & 21 & All low & $\begin{array}{l}3 \times \text { yes }^{44,48,51} \\
18 \times \mathrm{no}^{19,25,26,34,39-42,46,47,49,52-58}\end{array}$ & $\begin{array}{l}\text { No association } \\
\text { (limited evidence) }\end{array}$ \\
\hline II. Perceived stress/stressors & 8 & All low & $\begin{array}{l}2 \times \text { yes }^{46,59} \\
6 \times \text { no }^{19,42,47,50,53,55}\end{array}$ & $\begin{array}{l}\text { No association } \\
\text { (limited evidence) }\end{array}$ \\
\hline
\end{tabular}

\section{Personality traits}

One of eight studies showed a multivariate, longitudinal association between the category of personality traits and medication non-adherence: ${ }^{26}$ a lower sense of coherence (a global life orientation in which life is perceived as comprehensible, manageable and meaningful $)^{63}$ was associated with greater non-adherence (OR=0.55, CI 0.31-0.96). Associations between other predictors within the personality traits category and non-adherence were lacking.

\section{Psychological well-being}

Regarding categories EI (mood state) and EII (perceived stress/stressors), no associations between predictors in those categories and medication non-adherence could be established for the vast majority of studies (24 out of 29). Two of the five studies which did show significant associations reported on multivariate analyses: the regression coefficient for depressive symptoms was 0.18 (95\% CI 0.07, $0.29)$ in predicting non-adherence, ${ }^{51}$ the standardized beta for health distress was -0.22 (CI not reported) for predicting adherence. ${ }^{59}$

Table S2 can be consulted for detailed information about associations between single psychosocial predictors and medication adherence/non-adherence.

\section{Sensitivity analyses}

The sensitivity analyses confirmed that, generally, no association was found between the psychosocial categories and medication non-adherence (Table S4).

The additional analysis on single predictors showed no association between most single, psychosocial predictors and medication non-adherence. However, conflicting evidence was found for having a positive attitude towards taking medication, ${ }^{37,43}$ necessity beliefs and concern beliefs about medication, ${ }^{33,49}$ self-efficacy in medication-taking, ${ }^{25,33,43,47,53,54}$ the coping style "planful problem solving", ${ }^{25,41}$ and (the number of) stressful (life) events. ${ }^{38,42,46}$ Limited evidence was found for an association between escape-avoidance coping and medication non-adherence, ${ }^{25,41,56,59}$ and for an association between receiving practical, social support and medication adherence. ${ }^{38,41}$

\section{Discussion}

To the best of our knowledge, this is the first systematic review summarizing evidence of longitudinal associations between psychosocial factors and non-adherence to CPMM, irrespective of somatic disease. Due to the low quality of the included studies, limited evidence was found for absence of longitudinal associations between categories of psychoso- 
cial predictors and medication non-adherence. In general, findings were robust according to sensitivity analyses.

Our findings of longitudinal associations between psychosocial factors and medication non-adherence are in line with the few conducted cross-sectional studies about associations between medication adherence, coping styles, personality traits, and psychosocial well-being (except depressive symptoms) in somatic conditions. The findings in these cross-sectional studies are ambiguous at best. ${ }^{8,6468}$ For example, an active coping style was associated with medication adherence in some studies ${ }^{8,68}$ but not in others, ${ }^{64,66}$ and stress was associated with lesser adherence in a study of Holt et al ${ }^{67}$ but was unrelated to non-adherence in a study of Ediger et al. ${ }^{65}$

In contrast to coping styles and personality traits, depression is often studied as possible predictor of medication non-adherence. Here, our results are not in line with results from other reviews, reporting depression to be a predictor of medication non-adherence. ${ }^{6,69-74}$ Initially, this discrepancy might be explained by the fact that clinical depression is within the scope of most other studies, but beyond the scope of our systematic review since we did not study morbidity as a predictor of non-adherence; instead, we studied depressive symptoms. Second, an explanation might be that those other reviews included studies with mainly cross-sectional designs. Feelings of depression might increase and decrease over the course of a disease. A high degree of depressive feelings might correlate well with non-adherent behavior at that same time, but just might not be predictive of non-adherent behavior in the future due to this changeability. Thus, longitudinal associations between depressive feelings and non-adherence might not be applicable.

This thought might also apply to discrepancies in findings between our review and other reviews on associations between beliefs about medication/treatment, poor social support, and non-adherence. These other reviews underline the importance of beliefs about medication/treatment and poor social support in predicting medication non-adherence $\mathrm{e}^{6,10,69-76}$ in contrast to our review findings, but again, those other reviews are mainly based on studies with cross-sectional designs.

In terms of internal validity, a strength of this review is that we, in contrast to others, systematically defined and categorized psychosocial factors. By doing so, we were able to 1) draw a concise number of conclusions about associations between psychosocial predictors and medication non-adherence in a reproducible manner; 2) address the heterogeneity between single, psychosocial predictors; and 3) address an important goal of a systematic review: converging information. The pitfall of categorization (eg, the possibility of overlooking significant associations between certain, single predictors and non-adherence, by pooling them with other types of [non-significant] predictors), was avoided by performing an extended sensitivity analysis on single predictors. This analysis revealed our conclusions to be robust for almost all single, psychosocial predictors included in this review.

Another strength of this review is that we systematically synthesized results using a best evidence synthesis in contrast to most other reviews, which tend to be characterized by narrative designs. ${ }^{6,10,69,70,73,74,76}$ Narrative designs often do not rely on systematic methods to assign weight of evidence; eg, by incorporating methodological quality of included studies. ${ }^{77}$ Although no review procedure eliminates the chance that reviewers' biases will affect the conclusions drawn, ${ }^{77}$ the application of a best evidence synthesis makes a review procedure transparent and reproducible.

A limitation of this systematic review is that we used chronic disease terms instead of medication terms in the search strategy and, consequently, we may have missed relevant studies about chronic preventive maintenance medication. However, we assume that the number of missed studies is minimal, since diseases are usually mentioned in medication adherence studies.

Another limitation could be the use of results of univariate analyses to draw conclusions about associations in the absence of multivariate analysis data, as univariate analyses could lead to an overestimating of the strength of associations. However, our sensitivity analyses on data from univariate analyses confirmed the robustness of our findings.

Concerning external validity, a strong feature of this review is that it focused exclusively on longitudinal associations between psychosocial predictors and medication non-adherence, thereby providing insight into the temporality and robustness of associations. However, only 5 of the 30 studies included in our review corrected for baseline non-adherence..$^{34,50,53,58,59}$ Failure to account for baseline non-adherence when suggesting predictive longitudinal associations is considered a liberal approach, ${ }^{78}$ since baseline non-adherence is likely to explain a substantial part of the variance in non-adherence over time. Because we did not find any associations using a liberal approach, however, we believe it is unlikely that handling a strict longitudinal approach in this review would have altered our findings.

Another limitation concerning external validity is that the poor quality of the included studies prevented us from drawing firm conclusions about the lack of associations between psychosocial predictors and medication adherence 
The lack of a gold standard for adherence measurement ${ }^{73}$ also restricts the validity of our findings. The adherence measures used in the included studies of this review (self-report, refill data, and electronic monitoring) do not measure actual ingestion, and the use of self-report and electronic monitoring might have introduced response bias because of participants' awareness of the measurements. However, all medication adherence related research has to deal with the limitations of adherence measurements. For now, our review provides the best evidence currently available, and clearly demonstrates the need for more high-quality, longitudinal research into associations between psychosocial predictors and medication non-adherence.

Two recommendations for future research can be made. First, future longitudinal research into psychosocial predictors of medication non-adherence should be of high quality. Researchers should, for example, use valid measures of psychosocial predictors and medication non-adherence and should thoroughly describe which steps were performed in the study, especially those relating to handling missing data and avoiding bias.

Second, the research gap in longitudinal studies into associations between psychosocial predictors and medication non-adherence in patients with conditions such as rheumatic diseases, migraine disorders, gout, glaucoma, and stomach ulcers (see Supplementary Materials) should be complemented. Although we assume that review findings will also apply to these diseases, this assumption needs to be confirmed.

The conclusion of this systematic review is that there is limited evidence for absence of longitudinal associations between psychosocial predictors and medication nonadherence. Consequently, our results do not provide psychosocial targets for the development of new interventions in clinical practice. However, the usefulness of psychosocial predictors in improving medication adherence should not be ruled out, as more high-quality research is needed to confirm or refute the conclusion of this review. Such future research could also further explore the associations found in this review between escape-avoidance coping and medication non-adherence, and between receiving practical, social support and medication adherence.

\section{Acknowledgments}

We would like to thank Linda Kwakkenbos for her contribution in defining the psychosocial categories, Lieke van der Aa for translating studies of the Spanish/Portuguese language and Victor Huiskes for selecting chronic preventive maintenance medication.

\section{Disclosure}

The authors report no conflicts of interest in this work.

\section{References}

1. ABC project team. Ascertaining barriers for compliance: policies for save, effective and cost-effective use of medicines in Europe. Final report of the ABC-Project. Lodz, Poland: ABC Project; 2012. Available from: http://abcproject.eu/index.php?page=publications. Accessed September 14, 2012.

2. World Health Organization. Adherence to long-term therapies. Evidence for action. Geneva: World Health Organization; 2003. Available from: http://whqlibdoc.who.int/publications/2003/9241545992.pdf. Accessed August 1, 2012.

3. van Dulmen S, Sluijs E, van Dijk L, de Ridder D, Heerdink R, Bensing J. Patient adherence to medical treatment: a review of reviews. BMC Health Serv Res. 2007;7:55.

4. Psaty BM, Koepsell TD, Wagner EH, LoGerfo JP, Inui TS. The relative risk of incident coronary heart disease associated with recently stopping the use of beta-blockers. JAMA. 1990;263(12):1653-1657.

5. Balkrishnan R, Christensen DB. Inhaled corticosteroid use and associated outcomes in elderly patients with moderate to severe chronic pulmonary disease. Clin Ther. 2000;22(4):452-469.

6. Elliott RA. Poor adherence to medication in adults with rheumatoid arthritis: reasons and solutions. Dis Manag Health Outcome. 2008;16(1):13-29.

7. Gauchet A, Tarquinio C, Fischer G. Psychosocial predictors of medication adherence among persons living with HIV. Int J Behav Med. 2007;14(3):141-150.

8. Gremigni P, Bacchi F, Turrini C, Cappelli G, Albertazzi A, Bitti PE. Psychological factors associated with medication adherence following renal transplantation. Clin Transplant. 2007;21(6):710-715.

9. Horne R, Weinman J. Patients' beliefs about prescribed medicines and their role in adherence to treatment in chronic physical illness. J Psychosom Res. 1999;47(6):555-567.

10. Kane SV, Robinson A. Review article: understanding adherence to medication in ulcerative colitis - innovative thinking and evolving concepts. Aliment Pharmacol Ther. 2010;32(9):1051-1058.

11. Morrison V, Fargher E, Parveen, $\mathrm{S}$ et al. Determinants of Patient Adherence to Antihypertensive Medication: A Multi-national Cross-sectional Study. Lodz, Poland: ABC Project; 2012. Available from: http://abcproj ect.eu/index.php?page=publications. Accessed July 10, 2013.

12. Osterberg L, Blaschke T. Adherence to medication. $N$ Engl J Med. 2005;353(5):487-497.

13. Unni E, Farris KB. Determinants of different types of medication nonadherence in cholesterol lowering and asthma maintenance medications: a theoretical approach. Patient Educ Couns. 2011;83(3):382-390.

14. Haynes RB, Ackloo E, Sahota N, McDonald HP, Yao X. Interventions for enhancing medication adherence [review]. Cochrane Database Syst Rev. 2008;2:CD000011.

15. Liberati A, Altman DG, Tetzlaff J, et al. The PRISMA statement for reporting systematic reviews and meta-analyses of studies that evaluate healthcare interventions: explanation and elaboration. BMJ. 2009; 339:b2700.

16. http://www.cbs.nl [homepage on the Internet]. Definitions. Someone with a Western background. Centraal Bureau voor de Statistiek; 2012. Available from: http://www.cbs.n1/en-GB/menu/methoden/begrippen/default. htm? Languageswitch $=$ on\&ConceptID $=1057$. Accessed November 11, 2012.

17. Osamor PE, Owumi BE. Factors associated with treatment compliance in hypertension in southwest Nigeria. J Health Popul Nutr. 2011;29(6):619-628

18. Martikainen P, Bartley M, LahelmaE. Psychosocial determinants of health in social epidemiology. Int J Epidemiol. 2002;31(6):1091-1093.

19. Holmes WC, Bilker WB, Wang H, Chapman J, Gross R. HIV/AIDSspecific quality of life and adherence to antiretroviral therapy over time. J Acquir Immune Defic Syndr. 2007;46(3):323-327. 
20. Kuo YF, Raji MA, Markides KS, Ray LA, Espino DV, Goodwin JS. Inconsistent use of diabetes medications, diabetes complications, and mortality in older mexican americans over a 7-year period: data from the Hispanic established population for the epidemiologic study of the elderly. Diabetes Care. 2003;26(11):3054-3060.

21. Mizuno R, Fujimoto S, Uesugi A, et al. Influence of living style and situation on the compliance of taking antihypertensive agents in patients with essential hypertension. Intern Med. 2008;47(19):1655-1661.

22. Murri R, Ammassari A, De Luca A, et al. Self-reported nonadherence with antiretroviral drugs predicts persistent condition. HIV Clin Trials. 2001;2(4):323-329.

23. Elamin MB, Flynn DN, Bassler D, et al. Choice of data extraction tools for systematic reviews depends on resources and review complexity J Clin Epidemiol. 2009;62(5):506-510.

24. Zaza S, Wright-De Agüero LK, Briss PA, et al. Data collection instrument and procedure for systematic reviews in the Guide to Community Preventive Services. Task Force on Community Preventive Services. Am J Prev Med. 2000;18(Suppl 1):44-74.

25. Deschamps AE, Graeve VD, van Wijngaerden E, et al. Prevalence and correlates of nonadherence to antiretroviral therapy in a population of HIV patients using Medication Event Monitoring System. AIDS Patient Care STDS. 2004;18(11):644-657.

26. Nabi H, Vahtera J, Singh-Manoux A, et al. Do psychological attributes matter for adherence to antihypertensive medication? The Finnish Public Sector Cohort Study. J Hypertens. 2008;26(11):2236-2243.

27. Hayden JA, Côté P, Bombardier C. Evaluation of the quality of prognosis studies in systematic reviews. Ann Intern Med. 2006;144(6): 427-437.

28. de Vet HC, Mokkink LB, Terwee CB, Hoekstra OS, Knol DL. Clinicians are right not to like Cohen's א. BMJ. 2013;346:f2125.

29. Streiner DL, Norman GR. Health Measurement Scales: A Practical Guide to Their Development and Use. 4th ed. New York: Oxford University Press; 2008

30. Verbeek J, Ruotsalainen J, Hoving JL. Synthesizing study results in a systematic review. Scand J Work Environ Health. 2012;38(3):282-290.

31. Newman S, Mulligan K. The psychology of rheumatic diseases. Baillieres Best Pract Res Clin Rheumatol. 2000;14(4):773-786.

32. Ogden J. Health Psychology: A Textbook. 3rd ed. England: Open University Press; 2004.

33. Ponieman D, Wisnivesky JP, Leventhal H, Musumeci-Szabó TJ, Halm EA. Impact of positive and negative beliefs about inhaled corticosteroids on adherence in inner-city asthmatic patients. Ann Allergy Asthma Immunol. 2009;103(1):38-42.

34. Venturini F, Nichol MB, Sung JC, Bailey KL, Cody M, McCombs JS. Compliance with sulfonylureas in a health maintenance organization: a pharmacy record-based study. Ann Pharmacother. 1999;33(3): 281-288.

35. Gazmararian JA, Kripalani S, Miller MJ, Echt KV, Ren J, Rask K. Factors associated with medication refill adherence in cardiovascularrelated diseases: a focus on health literacy. J Gen Intern Med. 2006; 21(12):1215-1221.

36. Grégoire J, Moisan J, Guibert R, Ciampi A, Milot A. Predictors of self-reported noncompliance with antihypertensive drug treatment: a prospective cohort study. Can J Cardiol. 2006;22(4):323-329.

37. Miller P, Wikoff RL, McMahon M, Garrett MJ, Ringel K. Indicators of medical regimen adherence for myocardial infarction patients. Nurs Res. 1985;34(5):268-272.

38. Molloy GJ, Perkins-Porras L, Bhattacharyya MR, Strike PC, Steptoe A. Practical support predicts medication adherence and attendance at cardiac rehabilitation following acute coronary syndrome. J Psychosom Res. 2008;65(6):581-586.

39. Delgado J, Heath KV, Yip B, et al. Highly active antiretroviral therapy: physician experience and enhanced adherence to prescription refill. Antivir Ther. 2003;8(5):471-478.

40. Singh N, Squier C, Sivek C, Wagener M, Nguyen MH, Yu VL. Determinants of compliance with antiretroviral therapy in patients with human immunodeficiency virus: prospective assessment with implications for enhancing compliance. AIDS Care. 1996;8(3):261-269.
41. Singh N, Berman SM, Swindells S, et al. Adherence of human immunodeficiency virus-infected patients to antiretroviral therapy. Clin Infect Dis. 1999;29(4):824-830.

42. Bottonari KA, Roberts JE, Ciesla JA, Hewitt RG. Life stress and adherence to antiretroviral therapy among HIV-positive individuals: a preliminary investigation. AIDS Patient Care STDS. 2005;19(11): 719-727.

43. Godin G, Côté J, Naccache H, Lambert LD, Trottier S. Prediction of adherence to antiretroviral therapy: a one-year longitudinal study. AIDS Care. 2005;17(4):493-504.

44. Kacanek D, Jacobson DL, Spiegelman D, Wanke C, Isaac R, Wilson IB. Incident depression symptoms are associated with poorer HAART adherence: a longitudinal analysis from the Nutrition for Healthy Living study. J Acquir Immune Defic Syndr. 2010;53(2): 266-272.

45. Martini M, D'Elia S, Paoletti F, et al. Adherence to HIV treatment: results from a 1-year follow-up study. HIV Med. 2002;3(1):62-64.

46. Mellins CA, Kang E, Leu CS, Havens JF, Chesney MA. Longitudinal study of mental health and psychosocial predictors of medical treatment adherence in mothers living with HIV disease. AIDS Patient Care STDS 2003;17(8):407-416.

47. Nilsson Schönnesson L, Diamond PM, Ross MW, Williams M, Bratt G. Baseline predictors of three types of antiretroviral therapy (ART) adherence: A 2-year follow-up. AIDS Care. 2006;18(4): 407-414.

48. Thrasher AD, Earp JA, Golin CE, Zimmer CR. Discrimination, distrust, and racial/ethnic disparities in antiretroviral therapy adherence among a national sample of HIV-infected patients. J Acquir Immune Defic Syndr. 2008;49(1):84-93.

49. Horne R, Cooper V, Gellaitry G, Date HL, Fisher M. Patients' perceptions of highly active antiretroviral therapy in relation to treatment uptake and adherence: the utility of the necessity-concerns framework. J Acquir Immune Defic Syndr. 2007;45(3):334-341.

50. Mugavero MJ, Raper JL, Reif S, et al. Overload: impact of incident stressful events on antiretroviral medication adherence and virologic failure in a longitudinal, multisite human immunodeficiency virus cohort study. Psychosom Med. 2009;71(9):920-926.

51. Carrieri MP, Leport C, Protopopescu C, et al. Factors associated with nonadherence to highly active antiretroviral therapy: a 5-year followup analysis with correction for the bias induced by missing data in the treatment maintenance phase. J Acquir Immune Defic Syndr. 2006;41(4):477-485.

52. Stilley CS, DiMartini AF, de Vera ME, et al. Individual and environmental correlates and predictors of early adherence and outcomes after liver transplantation. Prog Transplant. 2010;20(1):58-66; quiz 67.

53. De Geest S, Abraham I, Moons P, et al. Late acute rejection and subclinical noncompliance with cyclosporine therapy in heart transplant recipients. J Heart Lung Transplant. 1998;17(9):854-863.

54. Russell CL, Cetingok M, Hamburger KQ, et al. Medication adherence in older renal transplant recipients. Clin Nurs Res. 2010;19(2): $95-112$.

55. Weng FL, Israni AK, Joffe MM, et al. Race and electronically measured adherence to immunosuppressive medications after deceased donor renal transplantation. J Am Soc Nephrol. 2005;16(6):1839-1848.

56. Dew MA, Roth LH, Thompson ME, Kormos RL, Griffith BP. Medical compliance and its predictors in the first year after heart transplantation. J Heart Lung Transplant. 1996;15(6):631-645.

57. Dew MA, Dimartini AF, De Vito Dabbs A, et al. Adherence to the medical regimen during the first two years after lung transplantation. Transplantation. 2008;85(2):193-202.

58. Dobbels F, Vanhaecke J, Dupont L, et al. Pretransplant predictors of posttransplant adherence and clinical outcome: an evidence base for pretransplant psychosocial screening. Transplantation. 2009; 87(10):1497-1504.

59. DiMatteo MR, Sherbourne CD, Hays RD, et al. Physicians' characteristics influence patients' adherence to medical treatment: results from the Medical Outcomes Study. Health Psychol. 1993;12(2):93-102. 
60. Hoogendoorn WE, van Poppel MN, Bongers PM, Koes BW, Bouter LM. Systematic review of psychosocial factors at work and private life as risk factors for back pain. Spine (Phila Pa 1976). 2000;25(16):2114-2125.

61. Proper KI, Singh AS, van Mechelen W, Chinapaw MJ. Sedentary behaviors and health outcomes among adults: a systematic review of prospective studies. Am J Prev Med. 2011;40(2):174-182.

62. Vriezekolk JE, van Lankveld WG, Geenen R, van den Ende CH. Longitudinal association between coping and psychological distress in rheumatoid arthritis: a systematic review. Ann Rheum Dis. 2011;70(7):1243-1250.

63. Wrześniewski K, Włodarczyk D. Sense of coherence as a personality predictor of the quality of life in men and women after myocardial infarction. Kardiol Pol. 2012;70(2):157-163.

64. Cholowski K, Cantwell R. Predictors of medication compliance among older heart failure patients. Int J Older People Nurs. 2007;2(4): $250-262$.

65. Ediger JP, Walker JR, Graff L, et al. Predictors of medication adherence in inflammatory bowel disease. Am J Gastroenterol. 2007;102(7): 1417-1426.

66. Frazier PA, Davis-Ali SH, Dahl KE. Correlates of noncompliance among renal transplant recipients. Clin Transplant. 1994;8(6):550-557.

67. Holt EW, Muntner P, Joyce C, Morisky DE, Webber LS, KrouselWood M. Life events, coping, and antihypertensive medication adherence among older adults: the cohort study of medication adherence among older adults. Am J Epidemiol. 2012;176 Suppl 7:S64-S71.

68. Smalls BL, Walker RJ, Hernandez-Tejada MA, Campbell JA, Davis KS, Egede LE. Associations between coping, diabetes knowledge, medication adherence and self-care behaviors in adults with type 2 diabetes. Gen Hosp Psychiatry. 2012;34(4):385-389.

69. Bailey CJ, Kodack M. Patient adherence to medication requirements for therapy of type 2 diabetes. Int J Clin Pract. 2011;65(3): 314-322.
70. Hawthorne AB, Rubin G, Ghosh S. Review article: medication nonadherence in ulcerative colitis - strategies to improve adherence with mesalazine and other maintenance therapies. Aliment Pharmacol Ther. 2008;27(12):1157-1166.

71. Jackson CA, Clatworthy J, Robinson A, Horne R. Factors associated with non-adherence to oral medication for inflammatory bowel disease: a systematic review. Am J Gastroenterol. 2010;105(3):525-539.

72. Odegard PS, Capoccia K. Medication taking and diabetes: a systematic review of the literature. Diabetes Educ. 2007;33(6):1014-1029; discussion 1030-1031.

73. van den Bemt BJ, Zwikker HE, van den Ende CH. Medication adherence in patients with rheumatoid arthritis: a critical appraisal of the existing literature. Expert Rev Clin Immunol. 2012;8(4):337-351.

74. Wu JR, Moser DK, Lennie TA, Burkhart PV. Medication adherence in patients who have heart failure: a review of the literature. Nurs Clin North Am. 2008;43(1):133-153; vii.

75. Ammassari A, Trotta MP, Murri R, et al; AdICoNA Study Group. Correlates and predictors of adherence to highly active antiretroviral therapy: overview of published literature. JAcquir Immune Defic Syndr. 2002;31 Supp1 3:S123-S127.

76. Restrepo RD, Alvarez MT, Wittnebel LD, et al. Medication adherence issues in patients treated for COPD. Int J Chron Obstruct Pulmon Dis. 2008;3(3):371-384.

77. Slavin RE. Best evidence synthesis: an intelligent alternative to meta-analysis. J Clin Epidemiol. 1995;48(1):9-18.

78. Overman CL, Bossema ER, van Middendorp H, et al. The prospective association between psychological distress and disease activity in rheumatoid arthritis: a multilevel regression analysis. Ann Rheum Dis. 2012;71(2):192-197. 


\section{Supplementary materials \\ Pubmed search strategy}

$((($ adult $[\mathrm{MeSH}$ Terms] OR mature[tw] OR adult[tw])

\section{AND}

((Ischaemic heart diseases[TW] OR angina pectoris[TW] OR Myocardial Ischemia[TW] OR asthma[TW] OR Diabetes mellitus[TW] OR diabetes mellitus[TW] OR hypercholesterolaemia[TW] OR hyperlipidaemia[TW] OR Dyslipidemias[TW] OR Gastric ulcer[TW] OR Duodenal ulcer[TW] OR Stomach Ulcer[TW] OR glaucoma[TW] OR glaucoma[TW] OR heart failure[TW] OR Heart failure[TW] OR arrhythmias[TW] OR Arrhythmias, Cardiac[TW] OR "Human immunodeficiency virus" OR HIV disease[TW] OR HIV-disease[TW] OR HIV infections[TW] OR HIV-infections[TW] OR Hypertensive diseases[TW] OR Hypertension[TW] OR Ulcerative colitis[TW] OR Crohn's disease[TW] OR Inflammatory Bowel Diseases[TW] OR Arthropathies[TW] OR gout[TW] OR Malignant neoplasm of breast[TW] OR Breast Neoplasms[TW] OR Hereditary angioedema[TW] OR Angioedemas, Hereditary[TW] OR transplantation[TW] OR Organ Transplantation[TW] OR migraine[TW] OR Migraine Disorders[TW] OR osteoporosis[TW] OR arthropathy[TW] OR Systemic connective tissue disorders[TW] OR psoriatic arthropathy[TW] OR rheumatoid arthritis[TW] OR Systemic lupus erythematosus[TW] OR Systemic sclerosis[TW] OR Arthritis, Psoriatic[TW] OR Arthritis, Rheumatoid[TW] OR Lupus Erythematosus, Systemic[TW] OR Scleroderma, Systemic[TW] OR Arterial embolism[TW] OR thrombosis[TW] OR venous embolism[TW] OR Embolism and Thrombosis[TW] OR Paget Disease[TW] OR Osteitis Deformans[TW]) OR (Myocardial Ischemia[MH] OR asthma[MH] OR diabetes mellitus[MH] OR Dyslipidemias[MH] OR Stomach Ulcer[MH] OR glaucoma[MH] OR Heart failure[MH] OR Arrhythmias, Cardiac[MH] OR HIV infections[MH] OR Hypertension[MH] OR Inflammatory Bowel Diseases[MH] OR gout[MH] OR Breast Neoplasms[MH] OR Angioedemas, Hereditary[MH] OR Organ Transplantation[MH] OR Migraine Disorders[MH] OR osteoporosis[MH] OR Arthritis, Psoriatic[MH] OR Arthritis, Rheumatoid[MH] OR Lupus Erythematosus, Systemic[MH] OR Scleroderma, Systemic[MH] OR Embolism and Thrombosis[MH] OR Osteitis Deformans[MH]))
AND

((medication adherence[MH] OR patient compliance[MH]) OR (medication compliance[TW] OR medication noncompliance[TW] OR medication non compliance[TW] OR medication noncompliance[TW] OR medication adherence[TW] OR medication non-adherence[TW] OR medication non adherence[TW] OR medication nonadherence[TW] OR medication adherance[TW] OR medication non-adherance[TW] OR medication non adherance[TW] OR medication nonadherance[TW] OR medication persistence[TW] OR medication non-persistence[TW] OR medication non persistence[TW] OR medication nonpersistence[TW] OR medication persistance[TW] OR medication non-persistance[TW] OR medication non persistance[TW] OR medication nonpersistance[TW] OR medicine compliance[TW] OR medicine noncompliance[TW] OR medicine non compliance[TW] OR medicine noncompliance[TW] OR medicine adherence[TW] OR medicine non-adherence[TW] OR medicine non adherence[TW] OR medicine nonadherence[TW] OR medicine adherance[TW] OR medicine non-adherance[TW] OR medicine non adherance[TW] OR medicine nonadherance[TW] OR medicine persistence[TW] OR medicine nonpersistence[TW] OR medicine non persistence[TW] OR medicine nonpersistence[TW] OR medicine persistance[TW] OR medicine non-persistance[TW] OR medicine non persistance[TW] OR medicine nonpersistance[TW] OR medical compliance[TW] OR medical non-compliance[TW] OR medical non compliance[TW] OR medical noncompliance[TW] OR medical adherence[TW] OR medical non-adherence[TW] OR medical non adherence[TW] OR medical nonadherence[TW] OR medical adherance[TW] OR medical non-adherance[TW] OR medical non adherance[TW] OR medical nonadherance[TW] OR medical persistence[TW] OR medical non-persistence[TW] OR medical non persistence[TW] OR medical nonpersistence[TW] OR medical persistance[TW] OR medical nonpersistance[TW] OR medical non persistance[TW] OR medical nonpersistance[TW] OR drug compliance[TW] OR drug non-compliance[TW] OR drug non compliance[TW] OR drug noncompliance[TW] OR drug adherence[TW] OR drug non-adherence[TW] OR drug non adherence[TW] OR drug nonadherence[TW] OR drug adherance[TW] OR drug non-adherance[TW] OR drug non adherance[TW] OR drug nonadherance[TW] OR drug persistence[TW] OR drug nonpersistence[TW] OR drug non persistence[TW] OR drug 
nonpersistence[TW] OR drug persistance[TW] OR drug nonpersistance[TW] OR drug non persistance[TW] OR drug nonpersistance[TW] OR drugs compliance[TW] OR drugs non-compliance[TW] OR drugs non compliance[TW] OR drugs noncompliance[TW] OR drugs adherence[TW] OR drugs non-adherence[TW] OR drugs non adherence[TW] OR drugs nonadherence[TW] OR drugs adherance[TW] OR drugs non-adherance[TW] OR drugs non adherance[TW] OR drugs nonadherance[TW] OR drugs persistence[TW] OR drugs non-persistence[TW] OR drugs non persistence[TW] OR drugs nonpersistence[TW] OR drugs persistance[TW] OR drugs non-persistance[TW] OR drugs non persistance[TW] OR drugs nonpersistance[TW]))

\section{AND}

(Prospective Studies[MH] OR Longitudinal Studies[MH] OR Cohort Studies[MH] OR Follow-up Studies[MH] OR Retrospective Studies[MH] OR Prospective Studies[TIAB] OR Longitudinal Studies[TIAB] OR Cohort Studies[TIAB] OR Follow-up Studies[TIAB] OR Retrospective Studies[TIAB] OR observational stud*[TIAB] OR predict*[TW] OR prognos*[TW] OR prognostic factor*[TW] OR course[TW] OR determinant*[TW]))

NOT

"Africa"[Mesh] OR "Latin America”[Mesh] OR

"Asia, Central"[Mesh] OR "Borneo"[Mesh] OR

"Brunei"[Mesh] OR "Cambodia"[Mesh] OR "East Timor"[Mesh] OR “Laos”[Mesh] OR “Malaysia”[Mesh] OR “Mekong Valley”[Mesh] OR “Myanmar”[Mesh] OR “Philippines"[Mesh] OR "Singapore"[Mesh] OR "Thailand"[Mesh] OR "Vietnam"[Mesh] OR "Bangladesh"[Mesh] OR "Bhutan"[Mesh] OR "India”[Mesh] OR “Afghanistan"[Mesh] OR “Bahrain"[Mesh] OR “Iran"[Mesh] OR “Egypt”[Mesh] OR “Iraq"[Mesh] OR “Israel”[Mesh] OR “Jordan"[Mesh] OR “Kuwait”[Mesh] OR “Lebanon”[Mesh] OR “Oman”[Mesh] OR “Qatar”[Mesh] OR "Saudi Arabia"[Mesh] OR "Syria"[Mesh] OR "United Arab Emirates"[Mesh] OR "Yemen"[Mesh] OR “Nepal”[Mesh] OR “Pakistan"[Mesh] OR "Sri Lanka”[Mesh] OR “China”[Mesh] OR “Korea”[Mesh] OR "Mongolia”[Mesh] OR “Taiwan”[Mesh]

NOT

(youth[TIAB] OR child*[TIAB] )

\section{NOT}

(Clinical Trial[MH] OR case reports[PT] OR review[PT] OR meta-analysis[MH] OR Cross-sectional Studies[MH] OR Case-control Studies[MesH:NoExp] OR Clinical Trial*[PT] OR case report*[PT] OR review*[PT] OR metaanalys*[PT] OR case report*[TIAB] OR case-report*[TIAB] OR review*[TIAB] OR systematic review*[TIAB] OR meta-analys*[TIAB] OR randomized controlled trial*[TIAB] OR randomised controlled trial*[TIAB] OR clinical trial*[TIAB] OR controlled clinical trial*[TIAB] OR cross-sectional*[TIAB] OR cross sectional*[TIAB] OR Case-control Studies[TIAB] OR case-control[TIAB] OR case control[TIAB] OR Editorial[ptyp] OR Letter[ptyp] OR Comment[ptyp] OR Interview[ptyp] OR Newspaper Article[ptyp])

\section{Chronic preventive maintenance medication}

A02BA01

A02BA02

A02BA03

A02BA04

A02BA07

A02BB01

A02BC01

A02BC02

A02BC03

A02BC04

A02BC05

A07EA04

A07EA06

A07EA07

A07EC01

A07EC02

A07EC03

A10A

A10BA02

A10BB01

A10BB03

A10BB07

A10BB09

A10BB 12

A10BF01

A10BG02

A10BG03

A10BH01

A10BX02

A11CC03 


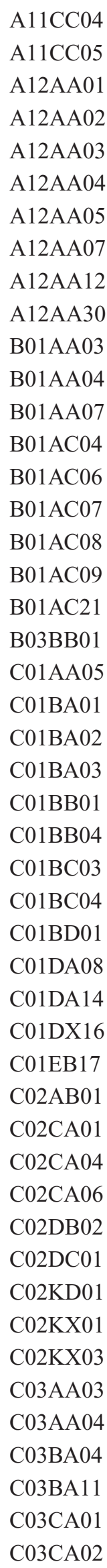

$\mathrm{A} 11 \mathrm{CC} 04$

A11CC05

A12AA01

A12AA02

A12AA04

A12AA05

A12AA07

A12AA12

B01AA03

B01AA04

B01AA07

$\mathrm{B} 01 \mathrm{AC} 04$

$\mathrm{B} 01 \mathrm{AC} 06$

$\mathrm{B} 01 \mathrm{AC} 07$

$\mathrm{B} 01 \mathrm{AC} 08$

$\mathrm{B} 01 \mathrm{AC} 09$

B03BB01

C01AA05

C01BA01

C01BA03

C01BB01

C01BB04

$\mathrm{C} 01 \mathrm{BC} 03$

$\mathrm{C} 01 \mathrm{BC} 04$

C01BD01

C01DA08

C01DX16

C01EB17

C02AB01

C02CA01

$\mathrm{C} 02 \mathrm{CA} 04$

C02CA06

C02DB02

$\mathrm{C} 02 \mathrm{DC} 01$

C02KD01

C02KX01

C02KX03

C03AA03

C03AA04

C03BA04

C03CA02
Calcitriol

Colecalciferol

Calciumphosphate

Calciumglubionate

Calciumgluconate

Calciumcarbonate

Calciumlactate

Calciumchloride

Calciumacetate

Calciumlevulinate

Warfarin

Fenprocoumon

Acenocoumarol

Clopidogrel

Acetylsalicylic acid

Dipyridamole

Carbasalate calcium

Epoprostenol

Treprostinil

Folic acid

Digoxin

Quinine

Procainamide

Disopyramide

Lidocaine

Aprindine

Propafenone

Flecainide

Amiodarone

Isosorbidedinitrate

Isosorbidemononitrate

Nicorandil

Ivabradine

Methyldopa

Prazosin

Doxazosin

Urapidil

Hydralazine

Minoxidil

Ketanserin

Bosentan

Sitaxentan

Hydrochloorthiazide

Chlorthiazide

Chlortalidone

Indapamide

Furosemide

Bumetanide
C03DA01

C03DA04

C03DB01

C03DB02

C04AC01

C04AD02

C07AA02

C07AA03

C07AA05

C07AA07

C07AB02

C07AB03

C07AB04

C07AB05

C07AB07

C07AB08

C07AB12

C07AG01

C07AG02

C08CA01

C08CA02

C08CA03

C08CA04

C08CA05

C08CA06

C08CA07

C08CA08

C08CA09

C08CA12

C08CA13

C08DA01

C08DB01

C09AA01

C09AA03

C09AA04

C09AA05

C09AA06

C09AA07

C09AA08

C09AA09

C09AA10

C09AA15

C09CA01

C09CA02

C09CA03

C09CA04

C09CA06

C09CA07
Spironolactone

Eplerenone

Amiloride

Triamterene

Nicotinic acid

Xantinolnicotinate

Oxprenolol

Pindolol

Propranolol

Sotalol

Metoprolol

Atenolol

Acebutolol

Betaxolol

Bisoprolol

Celiprolol

Nebivolol

Labetalol

Carvedilol

Amlodipine

Felodipine

Isradipine

Nicardipine

Nifedipine

Nimodipine

Nisoldipine

Nitrendipine

Lacidipine

Barnidipine

Lercanidipine

Verapamil

Diltiazem

Captopril

Lisinopril

Perindopril

Ramipril

Quinapril

Benazepril

Cilazapril

Fosinopril

Trandolapril

Zofenopril

Losartan

Eprosartan

Valsartan

Irbesartan

Candesartan

Telmisartan 


\begin{tabular}{|c|c|c|c|}
\hline C09CA08 & Olmesartan & J05AF02 & Didanosine \\
\hline C10AA01 & Simvastatin & J05AF03 & Zalcitabine \\
\hline C10AA03 & Pravastatin & J05AF04 & Stavudine \\
\hline C10AA04 & Fluvastatin & J05AF05 & Lamivudin \\
\hline C10AA05 & Atorvastatin & J05AF06 & Abacavir \\
\hline C10AA07 & Rosuvastatin & J05AF07 & Tenofovir \\
\hline C10AB01 & Clofibrate & J05AF08 & Adefovir \\
\hline C10AB02 & Bezafibrate & J05AF09 & Emtricitabine \\
\hline C10AB04 & Gemfibrozil & J05AF10 & Entecavir \\
\hline C10AB08 & Ciprofibrate & J05AF11 & Telbivudine \\
\hline $\mathrm{C} 10 \mathrm{AC} 01$ & Colestyramine & J05AG01 & Nevirapine \\
\hline C10AC02 & Colestipol & J05AG03 & Efavirenz \\
\hline $\mathrm{C} 10 \mathrm{AC} 04$ & Colesevelam & $\mathrm{J} 05 \mathrm{AX} 07$ & Enfuvirtide \\
\hline C10AD02 & Nicotinic acid & L01AA01 & Cyclophosphamide \\
\hline C10AD06 & Acipimox & L01BA01 & Methotrexate \\
\hline C10AX09 & Ezetimib & L02BG01 & Aminoglutethimide \\
\hline G03XA01 & Danazol & L02BG03 & Anastrozole \\
\hline G03XC01 & Raloxifene & L02BG04 & Letrozole \\
\hline G04BD02 & Flavoxate & L04AA06 & Mycophenol acid \\
\hline G04BD04 & Oxybutynin & L04AA10 & Sirolimus \\
\hline G04BD07 & Tolterodine & L04AA13 & Leflunomide \\
\hline G04BD08 & Solifenacin & L04AA18 & Everolimus \\
\hline G04BD10 & Darifenacin & L04AB01 & Etanercept \\
\hline G04CA01 & Alfuzosin & L04AB02 & Infliximab \\
\hline G04CA02 & Tamsulosin & L04AB04 & Adalimumab \\
\hline G04CA03 & Terazosin & $\mathrm{L} 04 \mathrm{AC} 03$ & Anakinra \\
\hline G04CB01 & Finasterid & L04AD01 & Ciclosporine \\
\hline G04CB02 & Dutasterid & L04AD02 & Tacrolimus \\
\hline H02AA02 & Fludrocortisone & L04AX01 & Azathioprine \\
\hline H02AB01 & Betamethasone & L04AX03 & Methotrexate \\
\hline H02AB02 & Dexamethasone & M01CB01 & Aurothiomalate \\
\hline H02AB04 & Methylprednisolone & M01CB03 & Auranofin \\
\hline H02AB06 & Prednisolone & M01CC01 & Penicillamine \\
\hline H02АB07 & Prednisone & M04AA01 & Allopurinol \\
\hline H02AB08 & Triamcinolone & M04AB01 & Probenecid \\
\hline H02АВ09 & Hydrocortisone & M04AB03 & Benzbromarone \\
\hline H02AB10 & Cortisone & M05BA01 & Etidronate \\
\hline J05AE01 & Saquinavir & M05BA02 & Clodronate \\
\hline J05AE02 & Indinavir & M05BA03 & Pamidronate \\
\hline J05AE03 & Ritonavir & M05BA04 & Alendronate \\
\hline J05AE04 & Nelfinavir & M05BA05 & Tiludronate \\
\hline J05AE05 & Amprenavir & M05BA06 & Ibandronate \\
\hline J05AE06 & Lopinavir & M05BA07 & Risedronate \\
\hline J05AE07 & Fosamprenavir & M05BA08 & Zoledronate \\
\hline J05AE08 & Atazanavir & M05BX03 & Strontiumranelate \\
\hline J05AE09 & Tipranavir & N02CX01 & Pizotifen \\
\hline J05AE10 & Darunavir & N02CX02 & Clonidine \\
\hline J05AF01 & Zidovudine & R03BA01 & Beclomethasone \\
\hline
\end{tabular}




R03BA02
R03BA05
R03BA08
R03BC01
R03BC03
R03DC03
S01EA02
S01EA03
S01EA05
S01EA51
S01EB01
S01EB08

R03BA02

S01EB08
Budesonide

Fluticasone

Ciclesonid

Cromolyn sodium

Nedocromil

Montelukast

Dipivefrine

Apraclonidine

Brimonidine

Epinephrine

Pilocarpine

Aceclidine
S01EC01

S01EC03

S01EC04

S01ED01

S01ED02

S01ED03

S01ED04

S01ED05

S01ED06

S01EE01

S01EE03

S01EE04
Acetazolamide

Dorzolamide

Brinzolamide

Timolol

Betaxolol

Levobunolol

Metipranolol

Carteolol

Befunolol

Latanoprost

Bimatoprost

Travoprost 
Table SI Framework for judging methodological quality

\begin{tabular}{ll}
\hline Bias domain & Criterion \\
\hline I. Study participation & I.I. The setting of the source population is adequately described by key characteristics (setting/geographical \\
location)
\end{tabular}
location)

1.2. The (baseline) study sample is adequately described by key characteristics (descriptive data about age, sex, diagnosis, disease duration and medication type/group), and no unacceptable level of bias is present

1.3. The method of recruitment or sampling is adequately described. If method of recruitment is not 'consecutive', then, for example, descriptions are given about the sampling frame, numbers, methods to identify the sample (such as a description of referral patterns in health care) and period of recruitment, and no unacceptable level of bias is present

1.4. Inclusion and exclusion criteria are adequately described, and no unacceptable level of bias is present

1.5. There is adequate participation in the study by eligible individuals (power analysis is described or the sample size $(n)$ is adequate in relation to the number of prognostic variables $(K)$ in the statistical analyses (ratio n:K exceeds 10:I)

2. Study attrition

2.I. Response rate (ie, proportion of study sample completing the study and providing outcome data) is adequate

If study sample size $\leq 50$ participants: 'yes' when total number of participants lost to follow-up was $<10 \%$ at followup $\geq$ three months. 'Partly': if this percentage was between $10 \%$ and $20 \%$. 'No'. if this percentage was $\geq 20 \%$ If study sample size $>50$ participants: 'yes', when total number of participants lost to follow-up was $<20 \%$ at follow-up \$three months. 'Partly': if this percentage was between $20 \%$ and $33 \%$. 'No': if this percentage was $\geq 33 \%$

2.2. Attempts to collect information about participants who dropped out of the study are described: I) reasons for loss to follow-up are provided OR 2) participants lost to follow-up are adequately described by key characteristics and outcomes. No unacceptable level of bias is present

3. Prognostic factor measurement
3.I. A clear description of the main prognostic factors is provided (not covariates) AND/OR measures/ methods regarding the main prognostic factors, at baseline and follow-up are adequately described to allow assessment of their validity and reliability. No unacceptable level of bias is present

$\circ$ Objective measures (such as number of life-changing events) and clear description is 'yes'. Poor/no description $=$ 'partly'

- Validated, subjective measures (eg, opinions) and clear description = 'yes'. Poor/no description = 'partly'

- Non-validated, subjective measures and clear description = 'partly'. Poor/no description = 'no'

3.2. The method and setting of measurement are the same for all study participants at baseline and follow-up

3.3. Continuous variables are reported or appropriate cut-off points are used

3.4. Authors appropriately described and dealt with missing data on prognostic factors
4.I. A clear description of medication adherence is provided AND/OR measures/methods of medication adherence (at baseline and follow-up) are adequately described, to allow assessment of their validity and reliability. No unacceptable level of bias is present

- Objective measures (such as pill count, refill rates, MEMS) and clear description = 'yes'. Poor/no description is 'partly'

- Validated, subjective measures (eg, questionnaires) and clear description = 'yes'. Poor/no description = 'partly'

- Non-validated, subjective measures and clear description = 'partly'. Poor/no description = 'no'

4.2. The method and setting of measurement are the same for all study participants at baseline (if measured) and follow-up

4.3. Authors appropriately described and dealt with missing outcome data
5.I. The most important confounders are measured

Examples of possible confounders: age; socioeconomic status/educational level/financial situation/illiteracy; social support/networks; depression/anxiety/emotional distress/lack of acceptance of disease; fatigue/pain/ physical disability; self-efficacy/coping; regimen complexity/route of administration/number of medications; satisfaction with patient-provider relationship/autonomy 


\begin{tabular}{|c|c|c|}
\hline Score & Judgment & Final score \\
\hline \multirow[t]{3}{*}{$\bigcirc$ Yes $\bigcirc$ Partly $\bigcirc$ No } & $5 \times$ yes $=$ yes & O Yes \\
\hline & $\mathrm{I} \times \mathrm{no}=\mathrm{no}$ & O Partly \\
\hline & Else $=$ partly & O No \\
\hline \multicolumn{3}{|l|}{ O Yes O Partly O No } \\
\hline \multicolumn{3}{|l|}{ O Yes $\bigcirc$ Partly $\bigcirc$ No } \\
\hline \multicolumn{3}{|l|}{ O Yes O Partly O No } \\
\hline \multicolumn{3}{|l|}{ O Yes $\bigcirc$ Partly $\bigcirc$ No } \\
\hline \multirow[t]{4}{*}{ O Yes $O$ Partly $\bigcirc$ No } & 2.1 yes = yes (you can leave 2.2 open) & O Yes \\
\hline & $2.1 \mathrm{no}=\mathrm{no}$ & Partly \\
\hline & OR 2.1 partly, 2.2 no = no & O No \\
\hline & Else $=$ partly & \\
\hline \multicolumn{3}{|l|}{ O Yes $\bigcirc$ Partly O No } \\
\hline \multirow[t]{4}{*}{ O Yes O Partly O No } & $4 \times$ yes $=$ yes & O Yes \\
\hline & 3.1 or $3.2 \mathrm{no}=$ no & O Partly \\
\hline & OR 3.1 or 3.2 partly (no no's), 3.3 or 3.4 no $=$ no & O No \\
\hline & Else $=$ partly & \\
\hline \multicolumn{3}{|l|}{ O Yes O Partly O No } \\
\hline \multicolumn{3}{|l|}{$O$ Yes $\bigcirc$ Partly $\bigcirc$ No } \\
\hline \multicolumn{3}{|l|}{ O Yes O Partly O No } \\
\hline \multirow[t]{4}{*}{ O Yes $O$ Partly $\bigcirc$ No } & $3 \times$ yes $=$ yes & O Yes \\
\hline & 4.1 or 4.2 no $=$ no & O Partly \\
\hline & OR 4.1 or 4.2 partly (no no's), 4.3 no $=$ no & O No \\
\hline & Else $=$ partly & \\
\hline \multicolumn{3}{|l|}{ O Yes $\bigcirc$ Partly $\bigcirc$ No } \\
\hline O Yes $\bigcirc$ Partly $\bigcirc$ No & & \\
\hline
\end{tabular}


Table SI (Continued)

\begin{tabular}{|c|c|}
\hline Bias domain & Criterion \\
\hline & $\begin{array}{l}\text { 5.2. A clear description of the most important confounders measured is provided AND/OR measures/ } \\
\text { methods of the most important confounders (at baseline) are adequately described to allow assessment of } \\
\text { their validity and reliability. No unacceptable level of bias is present } \\
\circ \text { Objective measures (such as age, sex) and clear description = 'yes'. Poor/no description is 'partly' } \\
\circ \text { Validated, subjective measures (eg, opinions) and clear description = 'yes'. Poor/no description = 'partly' } \\
\circ \text { Non-validated, subjective measures and clear description = 'partly'. Poor/no description = 'no' }\end{array}$ \\
\hline & $\begin{array}{l}\text { 5.3. The method and setting of confounding measurement are the same for all study participants at baseline } \\
\text { 5.4. Important potential confounders are accounted for in the study design (eg, matching for key variables/ } \\
\text { restriction) OR in analysis (stratification/multivariate techniques) } \\
\text { 5.5. Authors appropriately described and dealt with missing confounding data }\end{array}$ \\
\hline 6. Analysis & $\begin{array}{l}\text { 6.I. There is sufficient presentation of data to assess the adequacy of the analysis } \\
\text { 'Yes', if main findings of the study and statistical methods used are clearly described: simple outcome data, } \\
\text { crude data and estimates of random variability should be reported, so that the reader can check the major } \\
\text { analyses and conclusions } \\
\text { 6.2. The statistical tests used to assess the main outcome are appropriate } \\
\text { For example, non-parametric methods should be used for small sample sizes } \\
\text { 6.3. The strategy for model building (ie, inclusion of variables) is appropriate, and is based on conceptual } \\
\text { thoughts, a framework or a model } \\
\text { For example: variables that do not correlate with the main outcome of interest are not used in } \\
\text { multivariate analysis. Proper variables are entered in logical steps into the multivariate model } \\
\text { 6.4. The selected model is adequate for the design of the study } \\
\text { For example: in repeated measures, a repeated-measure model should be used. If outcome is binominal, } \\
\text { logistic regression should be used, etcetera. If delta outcome is being investigated, models should to be } \\
\text { adjusted for baseline outcome values }\end{array}$ \\
\hline
\end{tabular}

Abbreviation: MEMS, medication event monitoring system. 


\begin{tabular}{|c|c|c|}
\hline Score & Judgment & Final score \\
\hline \multirow[t]{7}{*}{ O Yes O Partly O No } & One of 5.1 to $5.4=$ no (if 5.1 no, you can leave 5.2 to 5.5 open) & O Yes \\
\hline & OR 5.1 to 5.4 partly, 5.5 no $=$ no & Partly \\
\hline & All partly = partly & O No \\
\hline & OR 5.1 to 5.4 partly, 5.5 yes = partly & \\
\hline & OR none of 5.1 to 5.4 no, 5.5 no = partly & \\
\hline & OR 5.1 to 5.4 yes, 5.5 not yes = partly & \\
\hline & Else $=$ yes & \\
\hline \multicolumn{3}{|l|}{ O Yes O Partly O No } \\
\hline \multicolumn{3}{|l|}{ O Yes O Partly O No } \\
\hline \multicolumn{3}{|l|}{ O Yes O Partly O No } \\
\hline \multirow[t]{3}{*}{ O Yes O Partly O No } & $4 \times$ yes $=$ yes & O Yes \\
\hline & At least $\mathrm{I} \times$ no $=$ no & O Partly \\
\hline & Else $=$ partly & O No \\
\hline \multicolumn{3}{|l|}{ O Yes O Partly O No } \\
\hline
\end{tabular}

$\bigcirc$ Yes $\bigcirc$ Partly $\bigcirc$ No 
Table S2 Explanation of measures and results*

\begin{tabular}{|c|c|c|c|}
\hline \multirow[t]{2}{*}{ First author } & \multirow[t]{2}{*}{ Setting, n patients } & \multicolumn{2}{|l|}{ Measures } \\
\hline & & $\begin{array}{l}\text { Adherence }^{\dagger} \\
\text { follow-up period } \ddagger\end{array}$ & Psychosocial predictors ${ }^{\S}$ \\
\hline \multicolumn{4}{|c|}{ Asthma (inhaled corticosteroids) } \\
\hline \multirow[t]{8}{*}{ Ponieman' } & $\begin{array}{l}\text { USA; patients from general internal } \\
\text { medicine clinic, } n=26 \text { I }\end{array}$ & $\begin{array}{l}\text { Adherence by self-report } \\
\text { (MARS), } 3 \text { months }\end{array}$ & $\begin{array}{l}\text { (Items derived from BMQ and Self-Regulation Theory): } \\
\text { concerns beliefs: worried about side effects of ICS? }\end{array}$ \\
\hline & & & Concerns beliefs: worried about getting addicted to ICS? \\
\hline & & & Concerns beliefs: if I use ICS all the time they will stop working \\
\hline & & & Necessity beliefs: important to use ICS when symptomatic? \\
\hline & & & Necessity beliefs: important to use ICS when asymptomatic? \\
\hline & & & Self-efficacy: confident in ability to use ICS as prescribed \\
\hline & & & Self-efficacy: confident in ability to control asthma \\
\hline & & & Self-efficacy: confident in controlling future health \\
\hline \multicolumn{4}{|c|}{ Diabetes (oral and/or parenteral anti-diabetics) } \\
\hline Venturini $\mathrm{i}^{2,59}$ & $\begin{array}{l}\text { USA; patients from HMO-providing } \\
\text { health services, } n=786\end{array}$ & $\begin{array}{l}\text { Adherence by record } \\
\text { review (continuous }\end{array}$ & Perception of mental health (mood state, SF-36) \\
\hline & & measure corrected for & \\
\hline & & self-reported baseline & \\
\hline & & adherence), last time & \\
\hline & & point flexible, but within & \\
\hline & & 24 months & \\
\hline \multicolumn{4}{|c|}{ Heart disease and hypertension (cardiovascular medication) } \\
\hline Gazmararian ${ }^{3,\|\|}$ & $\begin{array}{l}\text { USA; community-dwelling patients, } \\
\mathrm{n}=\mathrm{I}, 549\end{array}$ & $\begin{array}{l}\text { Non-adherence } \\
\text { by record review, } \\
12 \text { months }\end{array}$ & Social support (instrument NR) \\
\hline \multirow[t]{6}{*}{$\mathrm{Nabi}^{4}$} & $\begin{array}{l}\text { Finland: local government } \\
\text { employees, } n=|, 02|\end{array}$ & $\begin{array}{l}\text { Non-adherence by } \\
\text { record review (ordinal }\end{array}$ & Anxiety (ATS) \\
\hline & & measure), 12 months & Hostility (FTSSH) \\
\hline & & & Optimism (LOT-R) \\
\hline & & & Pessimism (LOT-R) \\
\hline & & & Psychological distress (GHQ) \\
\hline & & & Sense of coherence (SOC) \\
\hline \multirow[t]{3}{*}{ Grégoire $^{5}$} & $\begin{array}{l}\text { Canada: hypertensive adults with } \\
\text { prescription from network } \\
\text { of pharmacies, } n=692\end{array}$ & $\begin{array}{l}\text { Non-adherence by self- } \\
\text { report (Morisky Scale), } \\
3 \text { months }\end{array}$ & $\begin{array}{l}\text { (Interview, self-developed items): beliefs concerning efficacy } \\
\text { of antihypertensive medication } \\
\text { Beliefs concerning hypertension as risk factor for } \\
\text { other diseases }\end{array}$ \\
\hline & & & $\begin{array}{l}\text { How much are you at risk of a heart attack because of your } \\
\text { hypertension if you follow your doctor's advice? }\end{array}$ \\
\hline & & & $\begin{array}{l}\text { How much are you at risk of a stroke because of your } \\
\text { hypertension if you follow your doctor's advice? }\end{array}$ \\
\hline
\end{tabular}




\begin{tabular}{|c|c|c|c|c|}
\hline \multirow[t]{2}{*}{ Psychcat" } & \multicolumn{2}{|l|}{ Results" } & \multirow{2}{*}{$\begin{array}{l}\text { Direction of association } \\
\text { (regarding adherence)** }\end{array}$} & \multirow{2}{*}{$\begin{array}{l}\text { N domains } \\
\text { bias free }^{t t}\end{array}$} \\
\hline & Univariate & Multivariate & & \\
\hline Al & $\mathrm{OR}=0.3(0.2,0.7), P<0.05$ & $\mathrm{OR}=0.52(0.36,0.74), P<0.00 \mathrm{I}$ & $\begin{array}{l}\text { U: - } \\
\text { M:- }\end{array}$ & 0 of 6 \\
\hline $\mathrm{Al}$ & $\mathrm{OR}=0.4(0.2,0.8), P<0.05$ & $N S^{\ddagger}$ & $\begin{array}{l}\text { U: - } \\
\text { M: } 0\end{array}$ & \\
\hline $\mathrm{Al}$ & $\mathrm{OR}=0.4(0.2,0.9), P<0.05$ & NS & $\begin{array}{l}\text { U: }- \\
\text { M: } 0\end{array}$ & \\
\hline Al & NS & $N S^{\ddagger \ddagger}$ & $\begin{array}{l}\text { U: } 0 \\
\text { M: } 0\end{array}$ & \\
\hline $\mathrm{Al}$ & $\mathrm{OR}=5.8(2.3,14.6), P<0.05$ & $\mathrm{OR}=4.15(2.54,6.77), P<0.00 \mathrm{I}$ & $\begin{array}{l}\mathrm{U}:+ \\
\mathrm{M}:+\end{array}$ & \\
\hline Alll & $O R=3.5(1.6,7.6), P<0.05$ & $\mathrm{OR}=2.23(\mathrm{I} .42,3.52), P<0.00 \mathrm{I}$ & $\begin{array}{l}\mathrm{U}:+ \\
\mathrm{M}:+\end{array}$ & \\
\hline Alll & NS & NS & $\begin{array}{l}\text { U: } 0 \\
\text { M: } 0\end{array}$ & \\
\hline Alll & NS & 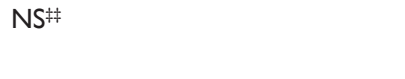 & $\begin{array}{l}\text { U: } 0 \\
\text { M: } 0\end{array}$ & \\
\hline $\mathrm{El}$ & NR & NS & $\begin{array}{l}\text { U: NR } \\
M: 0\end{array}$ & 2 of 6 \\
\hline CIII & NS & NT & $\begin{array}{l}\text { U: } 0 \\
\text { M: NT }\end{array}$ & 3 of 6 \\
\hline El & NS & NT & $\begin{array}{l}\text { U: } 0 \\
\text { M: NT }\end{array}$ & I of 6 \\
\hline D & NS & NT & $\begin{array}{l}\text { U: } 0 \\
\text { M: NT }\end{array}$ & \\
\hline D & NS & NT & $\begin{array}{l}\text { U: } 0 \\
\text { M: NT }\end{array}$ & \\
\hline$D$ & NS & NT & $\begin{array}{l}\text { U: } 0 \\
\text { M: NT }\end{array}$ & \\
\hline El & NS & NT & $\begin{array}{l}\text { U: } 0 \\
\text { M: NT }\end{array}$ & \\
\hline $\mathrm{D}$ & $O R=0.62(0.36,1.05), P<0.10$ & $\mathrm{OR}=0.55(0.3 \mathrm{I}, 0.96), P<0.05$ & $\begin{array}{l}\text { U: } 0 \\
\text { M: }+\end{array}$ & \\
\hline $\mathrm{Al}$ & NS & NS & $\begin{array}{l}\text { U: } 0 \\
\text { M: } 0\end{array}$ & 0 of 6 \\
\hline All & $\begin{array}{l}\text { "No effect" versus "a lot of effect" } \\
\text { (ref cat): OR }=1.74(1.08,2.81), P=0.02\end{array}$ & $\begin{array}{l}\text { "No effect" versus "a lot of effect": } \\
O R=2.00(I .21,3.33), P \leq 0.05\end{array}$ & $\begin{array}{l}\text { U: - } \\
\text { M: - }\end{array}$ & \\
\hline All & NS & NS & $\begin{array}{l}\text { U: } 0 \\
\text { M: } 0\end{array}$ & \\
\hline All & NS & NS & $\begin{array}{l}\text { U: } 0 \\
\text { M: } 0\end{array}$ & \\
\hline
\end{tabular}

(Continued) 
Table S2 (Continued)

\begin{tabular}{lll}
\hline First author $\quad$ Setting, n patients & Measures & \multicolumn{1}{c}{ Psychosocial predictors $^{\S}$} \\
\cline { 2 - 3 } & $\begin{array}{l}\text { Adherence } \\
\text { follow-up period }\end{array}$ & \\
\hline
\end{tabular}

$\begin{array}{cl}\text { Miller6,655 } & \begin{array}{l}\text { Site not reported: patients from } \\ \text { institutions providing cardiac } \\ \text { rehabilitation programs, } \mathrm{n}=141\end{array} \\ \text { Molloy, } 1.595 & \begin{array}{l}\text { UK; patients admitted to one of } \\ \text { four London hospitals with Acute } \\ \text { Coronary Syndrome, } \mathrm{n}=295\end{array}\end{array}$

HIV (antiretroviral medication)

Deschamps $^{8} \quad$ Belgium; outpatients of university hospital, $n=60$

How much are you at risk of heart attack because of your hypertension if you do not do anything about it?

How much are you at risk of stroke because of your hypertension if you do not do anything about it?

Social support (Pearlin et $\mathrm{al}^{31}$ )

Adherence by self-report (continuous measure, HBS), 6-9 months

Adherence by self-report, 12 months

Non-adherence by MEMS, 5-6 months after measuring psychosocial constructs
Attitude towards medication taking (MAS)

Beliefs about which steps of the medical regimen people most important to them think they should perform (HIS)

Emotional support (derived from Berkman et al ${ }^{32}$ and Seeman et $\mathrm{al}^{33}$ )

Practical support

Anxiety (AMHI)

Coping style: confrontational (AWC)

Coping style: distancing

Coping style: self-controlling

Coping style: seek social support

Coping style: accept responsibility

Coping style: escape-avoidance (higher score $=$ more escape-avoidance)

Coping style: planful problem solving (higher score $=$ more planful problem solving) "II II

Coping style: positive reappraisal

Depression (AMHI)

Perceived benefits of treatment (APIAQ)

Perceived severity of seriousness of implications when not taking medications adequately

Perceived susceptibility of developing AIDS when not taking medications as prescribed

Positive affect (eg, happiness person)

Received social support (AGSRP)

Self-efficacy in taking HAART medication (ALTMBSES) 


\begin{tabular}{|c|c|c|c|c|}
\hline \multirow[t]{2}{*}{ Psychcat"I } & \multicolumn{2}{|l|}{ Results" } & \multirow{2}{*}{$\begin{array}{l}\text { Direction of association } \\
\text { (regarding adherence)** }\end{array}$} & \multirow{2}{*}{$\begin{array}{l}\text { N domains } \\
\text { bias free }^{t \dagger}\end{array}$} \\
\hline & Univariate & Multivariate & & \\
\hline \multirow[t]{2}{*}{ All } & "Do not know" versus "no to moderate risk" (ref cat): & NS & U: 0 & \\
\hline & $\mathrm{OR}=0.46(0.19,1.12), P=0.09$ & & M: 0 & \\
\hline \multirow[t]{2}{*}{ All } & "Do not know" versus "no to moderate risk" (ref cat): & "Do not know" versus "no to & U: 0 & \\
\hline & $\mathrm{OR}=0.44(0.17,1.16), P=0.10$ & $\begin{array}{l}\text { moderate risk": OR =0.40 }(0.15 \\
\text { I.09), } P=0.07\end{array}$ & M: 0 & \\
\hline \multirow[t]{2}{*}{ CIII } & NS & NS & U: 0 & \\
\hline & & & M: 0 & \\
\hline \multirow[t]{2}{*}{ Al } & NR & NS & U: NR & 0 of 6 \\
\hline & & & M: 0 & \\
\hline \multirow[t]{2}{*}{$\mathrm{Cll}$} & & NS & U: NR & \\
\hline & & & M: 0 & \\
\hline \multirow[t]{2}{*}{ CIII } & NS & NS & U: 0 & I of 6 \\
\hline & & & M: 0 & \\
\hline \multirow[t]{2}{*}{ CIII } & Number of patients providing practical support: & $\mathrm{OR}=2.12(1.06,4.26)$ & $\mathrm{U:}+$ & \\
\hline & $\begin{array}{l}0: 39.7 \% \text { adherent. I: } 40.5 \% \text { adherent. Two or } \\
\text { more: } 59.2 \% \text { adherent, } P=0.004\end{array}$ & $P=0.03$ & M: + & \\
\hline \multirow[t]{2}{*}{ El } & NS & NR & $\mathrm{U}: 0$ & I of 6 \\
\hline & & & $M: N R$ & \\
\hline \multirow[t]{2}{*}{$\mathrm{BI}$} & NS & & $\mathrm{U}: 0$ & \\
\hline & & & $M: N R$ & \\
\hline \multirow[t]{2}{*}{ BII } & NS & & $\mathrm{U}: 0$ & \\
\hline & & & $M: N R$ & \\
\hline \multirow[t]{2}{*}{ BII } & NS & & $\mathrm{U}: 0$ & \\
\hline & & & $M: N R$ & \\
\hline \multirow[t]{2}{*}{ CIII } & NS & & $\mathrm{U}: 0$ & \\
\hline & & & $M: N R$ & \\
\hline \multirow[t]{2}{*}{ BII } & NS & & $\mathrm{U}: 0$ & \\
\hline & & & $M: N R$ & \\
\hline \multirow[t]{2}{*}{ BII } & Adherent patients $7.2,(2.2)$ versus non- & & $\mathrm{U}:-$ & \\
\hline & adherent patients 10.1 (2.8), $P=0.003$ & & $M: N R$ & \\
\hline \multirow[t]{2}{*}{$\mathrm{BI}$} & Adherent patients 7.5 (median), 3 (IQR) versus non- & & $\mathrm{U}:-$ & \\
\hline & adherent patients 9 (median), 2 (IQR), $P=0.049$ & & $M: N R$ & \\
\hline \multirow[t]{2}{*}{$\mathrm{BI}$} & NS & & $\mathrm{U}: 0$ & \\
\hline & & & $M: N R$ & \\
\hline \multirow[t]{2}{*}{ El } & NS & & $\mathrm{U}: 0$ & \\
\hline & & & $M: N R$ & \\
\hline \multirow[t]{2}{*}{$\mathrm{Al}$} & Adherent patients $2 \mathrm{I}$ (3.5) versus non- & & $\mathrm{U}: 0$ & \\
\hline & adherent patients 18.7 (3.9), $P=0.07$ & & $M: N R$ & \\
\hline \multirow[t]{2}{*}{ Al } & NS & & $\mathrm{U:} 0$ & \\
\hline & & & $M: N R$ & \\
\hline $\mathrm{Al}$ & NS & & $\mathrm{U}: 0$ & \\
\hline & & & $M: N R$ & \\
\hline$D$ & NS & & $\mathrm{U}: 0$ & \\
\hline & & & $M: N R$ & \\
\hline CIII & NS & & $\mathrm{U}: 0$ & \\
\hline & & & $M: N R$ & \\
\hline AllI & NS & & $\mathrm{U}: 0$ & \\
\hline & & & $M: N R$ & \\
\hline
\end{tabular}


Table S2 (Continued)

\begin{tabular}{|c|c|c|c|}
\hline \multirow[t]{2}{*}{ First author } & \multirow[t]{2}{*}{ Setting, n patients } & \multicolumn{2}{|l|}{ Measures } \\
\hline & & $\begin{array}{l}\text { Adherence }{ }^{\dagger} \\
\text { follow-up period } \ddagger\end{array}$ & Psychosocial predictors ${ }^{\S}$ \\
\hline \multirow[t]{7}{*}{ Holmes ${ }^{9}$} & USA; HIV-clinic patients, $n=I 16$ & $\begin{array}{l}\text { Adherence by MEMS, } \\
\text { I } 2 \text { months (or when viral }\end{array}$ & Depressive symptoms (CES-D) \\
\hline & & $\begin{array}{l}\text { load of } \geq 1,000 \text { copies } / \mathrm{mL} \\
\text { was reached) }\end{array}$ & HIV-disclosure worries (HAT-QOL) \\
\hline & & & Health worries (higher score $=$ fewer worries) \\
\hline & & & Medication worries (higher score = fewer worries) \\
\hline & & & Provider trust \\
\hline & & & Social support (ISEL) \\
\hline & & & Stress (PSS) \\
\hline Delgado $^{10}$ & $\begin{array}{l}\text { Canada; patients enrolled in } \\
\text { community drug treatment } \\
\text { program, } n=316\end{array}$ & $\begin{array}{l}\text { Adherence by record } \\
\text { review, } 12 \text { months }\end{array}$ & Depressive symptoms (CES-D) \\
\hline \multirow[t]{7}{*}{ Singh" } & $\begin{array}{l}\text { USA; new veteran patients seen } \\
\text { at medical center, } n=52\end{array}$ & $\begin{array}{l}\text { Non-adherence by } \\
\text { record review, } 6 \text { months }\end{array}$ & Confusion and bewilderment (POMS) \\
\hline & & & Depression and dejection \\
\hline & & & Mood disturbance \\
\hline & & & Religious support (instrument NR) \\
\hline & & & Social support (instrument NR) \\
\hline & & & Symptoms of depression (BDI) \\
\hline & & & Tension and anxiety (POMS) \\
\hline \multirow[t]{12}{*}{ Singh ${ }^{12}$} & $\begin{array}{l}\text { Site not reported: patients in } \\
\text { HIV-medical centers, } n=138\end{array}$ & $\begin{array}{l}\text { Non-adherence by } \\
\text { record review, } 6 \text { months }\end{array}$ & $\begin{array}{l}\text { Coping style: active-behavioral focused (higher score = greater } \\
\text { applicability of coping style to patient, BMICIS) }\end{array}$ \\
\hline & & & Coping style: active-cognitive focused \\
\hline & & & Coping style: avoidant coping \\
\hline & & & Coping style: emotion-focused \\
\hline & & & Coping style: problem-focused \\
\hline & & & Hopelessness: future expectations \\
\hline & & & Hopelessness: loss of motivation (higher score = more \\
\hline & & & hopelessness, BHS) \\
\hline & & & Hopelessness: negative feelings about future \\
\hline & & & Hopelessness: total score \\
\hline & & & Quality of life: psychological functioning (MOS SF-36) \\
\hline & & & Satisfaction with social support: emotional (SSQ) \\
\hline
\end{tabular}




\begin{tabular}{|c|c|c|c|c|}
\hline \multirow[t]{2}{*}{ Psychcat" } & \multicolumn{2}{|l|}{ Results" } & \multirow{2}{*}{$\begin{array}{l}\text { Direction of association } \\
\text { (regarding adherence)** }\end{array}$} & \multirow{2}{*}{$\begin{array}{l}\text { N domains } \\
\text { bias free }^{\dagger t}\end{array}$} \\
\hline & Univariate & Multivariate & & \\
\hline \multirow[t]{2}{*}{ EI } & High adherence 12.6 (II.3), & NS & U: 0 & 2 of 6 \\
\hline & low adherence 16.5 (II.7), $P=0.06$ & & M: 0 & \\
\hline \multirow[t]{2}{*}{ All } & NS & NT & $\mathrm{U}: 0$ & \\
\hline & & & M: NT & \\
\hline \multirow[t]{2}{*}{ All } & High adherence 79.2 (23.9), & NS & U: 0 & \\
\hline & low adherence 70.4 (28.9), $P=0.06$ & & M: 0 & \\
\hline \multirow[t]{2}{*}{$\mathrm{Al}$} & High adherence 86.I (20.4), & NS & $\mathrm{U}: 0$ & \\
\hline & low adherence 83.3 ( 18.3$), P=0.06$ & & M: 0 & \\
\hline \multirow[t]{2}{*}{$\mathrm{Cl}$} & NS & NT & $\mathrm{U}: 0$ & \\
\hline & & & M: NT & \\
\hline \multirow[t]{2}{*}{ CIII } & NS & NT & U: 0 & \\
\hline & & & M: NT & \\
\hline \multirow[t]{2}{*}{ Ell } & High adherence I2.4 (7.8), & NS & $\mathrm{U}: 0$ & \\
\hline & low adherence I5.3 (8.2), $P=0.07$ & & M: 0 & \\
\hline \multirow[t]{3}{*}{ El } & Not reporting depression: $79.8 \%$ & NS & U: - & I of 6 \\
\hline & adherent, reporting depression: $68.1 \%$ & & M: 0 & \\
\hline & adherent, $P=0.02$ & & & \\
\hline \multirow[t]{2}{*}{ BII } & NS & NT & U: 0 & I of 6 \\
\hline & & & M: NT & \\
\hline \multirow[t]{2}{*}{ El } & Adherent I4.2 (SEM I.9), non-adherent & NS & $\mathrm{U:}-$ & \\
\hline & 22.I (SEM 3.4), $P=0.04$ & & M: 0 & \\
\hline \multirow[t]{2}{*}{ El } & $39 \%$ in adherent patients, $76 \%$ in & $\mathrm{OR}=\mathrm{I} .4(\mathrm{I} . \mathrm{I}, \mathrm{I} .8), \mathrm{P}=0.0 \mathrm{I}$ & U: - & \\
\hline & non-adherent patients, $P=0.03$ & & M: - & \\
\hline \multirow[t]{2}{*}{ CIII } & NS & NT & $\mathrm{U}: 0$ & \\
\hline & & & M: NT & \\
\hline \multirow[t]{2}{*}{ CIII } & NS & NT & $\mathrm{U}: 0$ & \\
\hline & & & M: NT & \\
\hline \multirow[t]{2}{*}{ El } & NS & NT & $\mathrm{U}: 0$ & \\
\hline & & & M: NT & \\
\hline \multirow[t]{2}{*}{ El } & NS & NT & $\mathrm{U}: 0$ & \\
\hline & & & M: NT & \\
\hline $\mathrm{BI}$ & (Mean score, SEM): non-adherent 5.2 & NR & $\mathrm{U:}+$ & 1 of 6 \\
\hline & $(0.5)$ versus adherent $6.6(0.2), P=0.01$ & & $M: N R$ & \\
\hline $\mathrm{BI}$ & NS & & U: 0 & \\
\hline & & & $M: N R$ & \\
\hline BII & Non-adherent $3.3(0.3)$ versus adherent & & $\mathrm{U}:-$ & \\
\hline & $2.6(0.2), P=0.02$ & & $M: N R$ & \\
\hline BII & NS & & $\mathrm{U:} 0$ & \\
\hline & & & $M: N R$ & \\
\hline $\mathrm{BI}$ & Non-adherent $6.0(0.5)$ versus adherent & & $\mathrm{U}:+$ & \\
\hline & $7 . I(0.2), P=0.02$ & & $M: N R$ & \\
\hline BII & NS & & $\mathrm{U}: 0$ & \\
\hline & & & $M: N R$ & \\
\hline BII & Non-adherent I.75 (0.5), adherent & & $\mathrm{U:-}$ & \\
\hline & $0.6(0.1), P=0.006$ & & $M: N R$ & \\
\hline BII & NS & & U: 0 & \\
\hline & & & $M: N R$ & \\
\hline BII & NS & & U: 0 & \\
\hline & & & M: NR & \\
\hline El & NS & & $\mathrm{U}: 0$ & \\
\hline & & & $M: N R$ & \\
\hline CIII & NS & & $\mathrm{U}: 0$ & \\
\hline & & & $M: N R$ & \\
\hline
\end{tabular}


Table S2 (Continued)

\begin{tabular}{|c|c|c|c|}
\hline \multirow[t]{2}{*}{ First author } & \multirow[t]{2}{*}{ Setting, $\mathbf{n}$ patients } & \multicolumn{2}{|l|}{ Measures } \\
\hline & & $\begin{array}{l}\text { Adherence }{ }^{\dagger} \\
\text { follow-up period } \ddagger\end{array}$ & Psychosocial predictors ${ }^{\S}$ \\
\hline & & & $\begin{array}{l}\text { Satisfaction with social support: informational } \\
\text { (higher scores = less satisfaction) }\end{array}$ \\
\hline & & & Satisfaction with social support: tangible \\
\hline & & & Satisfaction with social support: total score \\
\hline \multirow[t]{6}{*}{ Bottonari ${ }^{13}$} & $\begin{array}{l}\text { USA; patients treated in } \\
\text { immunodeficiency clinic, } n=78\end{array}$ & $\begin{array}{l}\text { Adherence by self- } \\
\text { report (straightforward), }\end{array}$ & Depressive symptoms (IDD) \\
\hline & & 6-9 months & Experience of general (stressful) life events (LES) \\
\hline & & & HIV-specific (stressful) life events (BHLES) \\
\hline & & & $\begin{array}{l}\text { Neuroticism: personality style indicative of affective instability } \\
\text { (NSEPQSS) }\end{array}$ \\
\hline & & & Perceived stress (PSS) \\
\hline & & & Self-esteem (RSEQR) \\
\hline \multirow[t]{4}{*}{ Godin $^{14}$} & $\begin{array}{l}\text { Canada; patients from medical } \\
\text { HIV-clinics, } n=400\end{array}$ & $\begin{array}{l}\text { Adherence over } \\
\text { time by self-report } \\
\text { (straightforward), } \\
12 \text { months }\end{array}$ & $\begin{array}{l}\text { Change in predictors related to adherence over time: attitude } \\
\text { towards medication-taking (more positive attitude = greater } \\
\text { adherence, self-developed scale) } \\
\text { Optimism (DOS) }\end{array}$ \\
\hline & & & $\begin{array}{l}\text { Outcome expectations (eg, believe that specific course of } \\
\text { action will lead to desired outcome, self-developed scale) } \\
\text { Patient-doctor satisfaction (Pat SS) }\end{array}$ \\
\hline & & & Self-efficacy regarding medication taking (self-developed scale) \\
\hline & & & Social support (SPS) \\
\hline Kacanek $^{15}$ & $\begin{array}{l}\text { USA; patients recruited by media } \\
\text { and physician networks, } n=225\end{array}$ & $\begin{array}{l}\text { Suboptimal adherence } \\
\text { by self-report } \\
\text { (straightforward): } \\
\text { max } 30 \text { months }\end{array}$ & Development of depressive symptoms (BST) \\
\hline \multirow[t]{3}{*}{ Martini $^{16, \$ \S \S}$} & $\begin{array}{l}\text { Italy; outpatients using combination } \\
\text { therapy, } \mathrm{n}=2 \mid 4\end{array}$ & $\begin{array}{l}\text { Adherence by self- } \\
\text { report (ordinal measure, } \\
\text { straightforward } \\
\text { questionnaire), } \\
\text { I } 2 \text { months }\end{array}$ & (Interview, instrument NR): perception of therapy: reliable? \\
\hline & & & Perception of therapy: enslaving? \\
\hline & & & $\begin{array}{l}\text { Satisfied about doctor/patient discussion regarding clinical and } \\
\text { therapeutic aspects of treatment? }\end{array}$ \\
\hline \multirow[t]{4}{*}{ Mellins ${ }^{17}$} & $\begin{array}{l}\text { USA; HIV-infected mothers } \\
\text { recruited in waiting room }\end{array}$ & $\begin{array}{l}\text { Non-adherence by } \\
\text { self-report (AACTG, }\end{array}$ & Negative stressful events (PEI) \\
\hline & of adult clinic, $n=128$ & $\begin{array}{l}\text { straightforward), } \\
\text { TI after } 4-5 \text { months, }\end{array}$ & Parenting stress (low scores = more stress, PPCS) \\
\hline & & T2 8-18 months after TI & $\begin{array}{l}\text { Psychological distress (aggregated demoralization score, } \\
\text { DSPERI) }\end{array}$ \\
\hline & & & $\begin{array}{l}\text { Self-efficacy in carrying out health-related behaviors } \\
\left(\text { Chesney et } \mathrm{al}^{34}\right)\end{array}$ \\
\hline
\end{tabular}




\begin{tabular}{|c|c|c|c|c|}
\hline \multirow[t]{2}{*}{ Psychcat" } & \multicolumn{2}{|l|}{ Results" } & \multirow{2}{*}{$\begin{array}{l}\text { Direction of association } \\
\text { (regarding adherence)** }\end{array}$} & \multirow{2}{*}{$\begin{array}{l}\text { N domains } \\
\text { bias free }^{t t}\end{array}$} \\
\hline & Univariate & Multivariate & & \\
\hline & & & $\mathrm{U:}+$ & \\
\hline \multirow[t]{2}{*}{ CIII } & Non-adherent $7.9(\mathrm{I} . \mathrm{I})$, adherent 6.1 (0.3), $P=0.04$ & & $M: N R$ & \\
\hline & & & U: 0 & \\
\hline \multirow[t]{2}{*}{ CIII } & Non-adherent 7.7 (I.I), adherent & & M: NR & \\
\hline & $5.5(0.3), P=0.07$ & & $\mathrm{U:}+$ & \\
\hline \multirow[t]{2}{*}{ CIII } & Non-adherent 22.9 (3.3), adherent & & M: NR & \\
\hline & $16.8(0.75), P=0.03$ & & & \\
\hline \multirow[t]{2}{*}{$\mathrm{El}$} & NS & NR & $\mathrm{U}: 0$ & 0 of 6 \\
\hline & & & M: NR & \\
\hline \multirow[t]{2}{*}{ Ell } & NS & & $\mathrm{U}: 0$ & \\
\hline & & & $M: N R$ & \\
\hline \multirow[t]{2}{*}{ Ell } & NS & & $\mathrm{U:} 0$ & \\
\hline & & & $M: N R$ & \\
\hline \multirow[t]{2}{*}{$\mathrm{D}$} & NS & & $\mathrm{U}: 0$ & \\
\hline & & & $M: N R$ & \\
\hline \multirow[t]{2}{*}{ Ell } & $\mathrm{OR}=0.88(0.77,0.98), P=0.04$ & & $\mathrm{U}:-$ & \\
\hline & & & $M: N R$ & \\
\hline \multirow[t]{2}{*}{ D } & NS & & $\mathrm{U}: 0$ & \\
\hline & & & $M: N R$ & \\
\hline \multirow[t]{2}{*}{$\mathrm{Al}$} & NR & $O R=1.56(1.18,2.06), P \leq 0.05$ & $U: N R$ & I of 6 \\
\hline & & & M: + & \\
\hline \multirow[t]{2}{*}{ D } & & NS & U: NR & \\
\hline & & & M: 0 & \\
\hline \multirow[t]{2}{*}{ Alll } & & NS & $U: N R$ & \\
\hline & & & M: 0 & \\
\hline \multirow[t]{2}{*}{$\mathrm{Cl}$} & & NS & $U: N R$ & \\
\hline & & & M: 0 & \\
\hline \multirow[t]{2}{*}{ Alll } & & $O R=1.68(1.27,2.22), P \leq 0.05$ & $U: N R$ & \\
\hline & & & $M:+$ & \\
\hline CIII & & NS & U: NR & \\
\hline & & & M: 0 & \\
\hline El & Suboptimal adherence in those who & NT & $\mathrm{U}:-$ & 2 of 6 \\
\hline & developed depressive symptoms $=45.1 \%$ & & M: NT & \\
\hline & versus $25.9 \%$ in those with no & & & \\
\hline & depressive symptoms, $P=0.0 \mathrm{I}$ & & & \\
\hline $\mathrm{Al}$ & In "high adherence" category, therapy & NR & $\mathrm{U}:+$ & 0 of 6 \\
\hline & perceived as "reliable" by I5.6\%, and "not reliable" & & $M: N R$ & \\
\hline & by $84.4 \%$. In "variable adherence" cat $4.8 \%$ versus & & & \\
\hline & $95.2 \%$. In "low adherence" cat $0 \%$ versus & & & \\
\hline & $100 \%, P=0.02$ & & & \\
\hline Al & NS & & $\mathrm{U}: 0$ & \\
\hline & & & $M: N R$ & \\
\hline $\mathrm{Cl}$ & In "high adherence" category: & & $\mathrm{U}: ?$ & \\
\hline & "sufficient/highly satisfied" = 73.9\%, & & $M: N R$ & \\
\hline & "little/not satisfied" = $26.1 \%$. In "variable & & & \\
\hline & adherence" cat $80 \%$ versus $20 \%$. In & & & \\
\hline & "low adherence" cat $50 \%$ versus $50 \%, P=0.05$ & & & \\
\hline Ell & $\mathrm{OR}=\mathrm{I} .27(\mathrm{I} .09, \mathrm{I} .49), \mathrm{P}<0.0 \mathrm{I}$ at $\mathrm{TI}$ & NR & $\mathrm{U}:-$ & 0 of 6 \\
\hline & $\mathrm{OR}=1.28(1.05,1.57), P=0.02$ at $\mathrm{T} 2$ & & M: NR & \\
\hline Ell & $\mathrm{OR}=0.86(0.76,0.98), P=0.02$ at $\mathrm{T} 2$ & & $\mathrm{U}:-$ & \\
\hline & & & $M: N R$ & \\
\hline El & NS & & $\mathrm{U}: 0$ & \\
\hline & & & $M: N R$ & \\
\hline Alll & NS & & U: 0 & \\
\hline & & & $M: N R$ & \\
\hline
\end{tabular}

(Continued) 
Table S2 (Continued)

\begin{tabular}{|c|c|c|c|}
\hline \multirow[t]{2}{*}{ First author } & \multirow[t]{2}{*}{ Setting, n patients } & \multicolumn{2}{|l|}{ Measures } \\
\hline & & $\begin{array}{l}\text { Adherence }{ }^{\dagger} \\
\text { follow-up period } \ddagger\end{array}$ & Psychosocial predictors ${ }^{\S}$ \\
\hline \multirow[t]{16}{*}{$\begin{array}{l}\text { Nilsson } \\
\text { Schönnesson }{ }^{18}\end{array}$} & $\begin{array}{l}\text { Sweden; patients recruited by } \\
\text { clinic nurses, } n=203\end{array}$ & $\begin{array}{l}\text { Adherence by self-report } \\
\text { (straightforward), }\end{array}$ & Anxiety symptoms (ASBSI) \\
\hline & & 24 months & Belief in adherence necessity (one item) \\
\hline & & & Belief that ART prolongs one's life (one item) \\
\hline & & & $\begin{array}{l}\text { Belief in future HIV-related health problems (self-developed } \\
\text { scale) }\end{array}$ \\
\hline & & & Belief in influencing HIV disease $(\mathrm{MAH})$ \\
\hline & & & $\begin{array}{l}\text { Beliefs in ART health concerns (eg, believe that medication } \\
\text { makes sicker, one item) }\end{array}$ \\
\hline & & & Coping mode: helplessness (MAH) \\
\hline & & & Coping mode: resilience (MAH) \\
\hline & & & Depressive symptoms (DSBSI) \\
\hline & & & Global social support satisfaction (one item) \\
\hline & & & Hopelessness (BHS) \\
\hline & & & Life stress (LSS) \\
\hline & & & Patient-provider relationship (self-developed scale) \\
\hline & & & $\begin{array}{l}\text { Perceived pressure to take HIV medication (self-developed } \\
\text { scale) }\end{array}$ \\
\hline & & & $\begin{array}{l}\text { Posttraumatic stress disorder symptoms related to HIV } \\
\text { diagnosis (HIE) }\end{array}$ \\
\hline & & & Self-efficacy in taking medication (self-developed scale) \\
\hline \multirow[t]{3}{*}{ Thrasher $^{19}$} & $\begin{array}{l}\text { USA; patients in public use } \\
\text { of HCSUS data-set, } n=I, 91 \mathrm{I}\end{array}$ & $\begin{array}{l}\text { Adherence by self-report } \\
\text { (straightforward), }\end{array}$ & (Instruments NR): depressive symptoms \\
\hline & & 12 months & Dysthymia symptoms \\
\hline & & & Social support \\
\hline \multirow[t]{3}{*}{ Horne $^{20}$} & $\begin{array}{l}\text { UK; outpatients, eligible to receive } \\
\text { HAART, } n=136\end{array}$ & $\begin{array}{l}\text { Adherence by self- } \\
\text { report (VAS-scale from }\end{array}$ & Depressive symptoms (HADS) \\
\hline & & $\begin{array}{l}\text { MASRI, straightforward), } \\
\text { I } 2 \text { months }\end{array}$ & HAART concern beliefs about medication (BMQ) \\
\hline & & & HAART necessity beliefs about medication \\
\hline \multirow[t]{5}{*}{ Mugavero ${ }^{21}$} & $\begin{array}{l}\text { USA; patients receiving care at one } \\
\text { of eight infectious disease clinics, }\end{array}$ & $\begin{array}{l}\text { Non-adherence by } \\
\text { self-report (AACTG, }\end{array}$ & Number of severe stressful events (LES, modified version) \\
\hline & $\mathrm{n}=474$ & $\begin{array}{l}\text { straightforward, } \\
\text { corrected for baseline }\end{array}$ & Number of stressful events (moderate + severe stressful events) \\
\hline & & non-adherence), & Number of traumatic events \\
\hline & & 27 months & \\
\hline & & & $\begin{array}{l}\text { Number of types of lifetime traumatic experiences (composite } \\
\text { measure of diverse questionnaires) }\end{array}$ \\
\hline
\end{tabular}




\begin{tabular}{|c|c|c|c|c|}
\hline \multirow[t]{2}{*}{ Psychcat" } & \multicolumn{2}{|l|}{ Results" } & \multirow{2}{*}{$\begin{array}{l}\text { Direction of association } \\
\text { (regarding adherence)** }^{* *}\end{array}$} & \multirow{2}{*}{$\begin{array}{l}\mathbf{N} \text { domains } \\
\text { bias free }^{t t}\end{array}$} \\
\hline & Univariate & Multivariate & & \\
\hline \multirow[t]{2}{*}{ El } & NR & NS & U: NR & I of 6 \\
\hline & & & M: 0 & \\
\hline \multirow[t]{2}{*}{$\mathrm{Al}$} & & NS & U: NR & \\
\hline & & & M: 0 & \\
\hline \multirow[t]{2}{*}{$\mathrm{Al}$} & & NS & U: NR & \\
\hline & & & M: 0 & \\
\hline \multirow[t]{2}{*}{ All } & & NS & U: NR & \\
\hline & & & M: 0 & \\
\hline \multirow[t]{2}{*}{ Alll } & & NS & U: NR & \\
\hline & & & M: 0 & \\
\hline \multirow[t]{2}{*}{$\mathrm{Al}$} & & NS & U: NR & \\
\hline & & & M: 0 & \\
\hline \multirow[t]{2}{*}{ BII } & & NS & U: NR & \\
\hline & & & M: 0 & \\
\hline \multirow[t]{2}{*}{ D } & & NS & U: NR & \\
\hline & & & M: 0 & \\
\hline \multirow[t]{2}{*}{ EI } & & NS & U: NR & \\
\hline & & & M: 0 & \\
\hline \multirow[t]{2}{*}{ CIII } & & NS & U: NR & \\
\hline & & & M: 0 & \\
\hline \multirow[t]{2}{*}{ BII } & & NS & U: NR & \\
\hline & & & M: 0 & \\
\hline \multirow[t]{2}{*}{ Ell } & & NS & U: NR & \\
\hline & & & M: 0 & \\
\hline \multirow[t]{2}{*}{$\mathrm{Cl}$} & & NS & U: NR & \\
\hline & & & M: 0 & \\
\hline \multirow[t]{2}{*}{ CIII } & & NS & U: NR & \\
\hline & & & M: 0 & \\
\hline \multirow[t]{2}{*}{ EI } & & NS & U: NR & \\
\hline & & & M: 0 & \\
\hline Alll & & NS & U: NR & \\
\hline & & & M: 0 & \\
\hline EI & $\mathrm{OR}=0.98(0.96,0.99), P=0.007$ & NR & $\mathrm{U:} \mathrm{-}$ & I of 6 \\
\hline & & & $M: N R$ & \\
\hline El & $\mathrm{OR}=0.92(0.87,0.96), P=0.00 \mathrm{I}$ & & U: - & \\
\hline & & & M: NR & \\
\hline CIII & NS & & U: 0 & \\
\hline & & & M: NR & \\
\hline EI & NS & NT & U: 0 & 3 of 6 \\
\hline & & & M: NT & \\
\hline $\mathrm{Al}$ & High adherence $2.9(0.6)$ versus low & $\mathrm{OR}=0.45(0.22,0.96), P=0.038$ & U: - & \\
\hline & adherence $3.3(0.6), P=0.005$ & & M: - & \\
\hline Al & High adherence $4.0(0.6)$ versus low & $\mathrm{OR}=2.19(\mathrm{I} .02,4.7 \mathrm{I}), P=0.045$ & $\mathrm{U:}+$ & \\
\hline & adherence $3.7(0.6), P=0.006$ & & M: + & \\
\hline Ell & OR (per event) $=I .14(1.03,1.26)$ & NS & U: - & 3 of 6 \\
\hline & & & M: 0 & \\
\hline Ell & OR (per event) $=1.09(1.04,1.13)$ & OR (per event) $=1.10(1.04,1.16)$ & U: - & \\
\hline & & & M: - & \\
\hline Ell & OR (per event) $=1.73(1.24,2.39)$ & NS & U: - & \\
\hline & & & M: 0 & \\
\hline Ell & NS & NS & U: 0 & \\
\hline & & & M: 0 & \\
\hline
\end{tabular}


Table S2 (Continued)

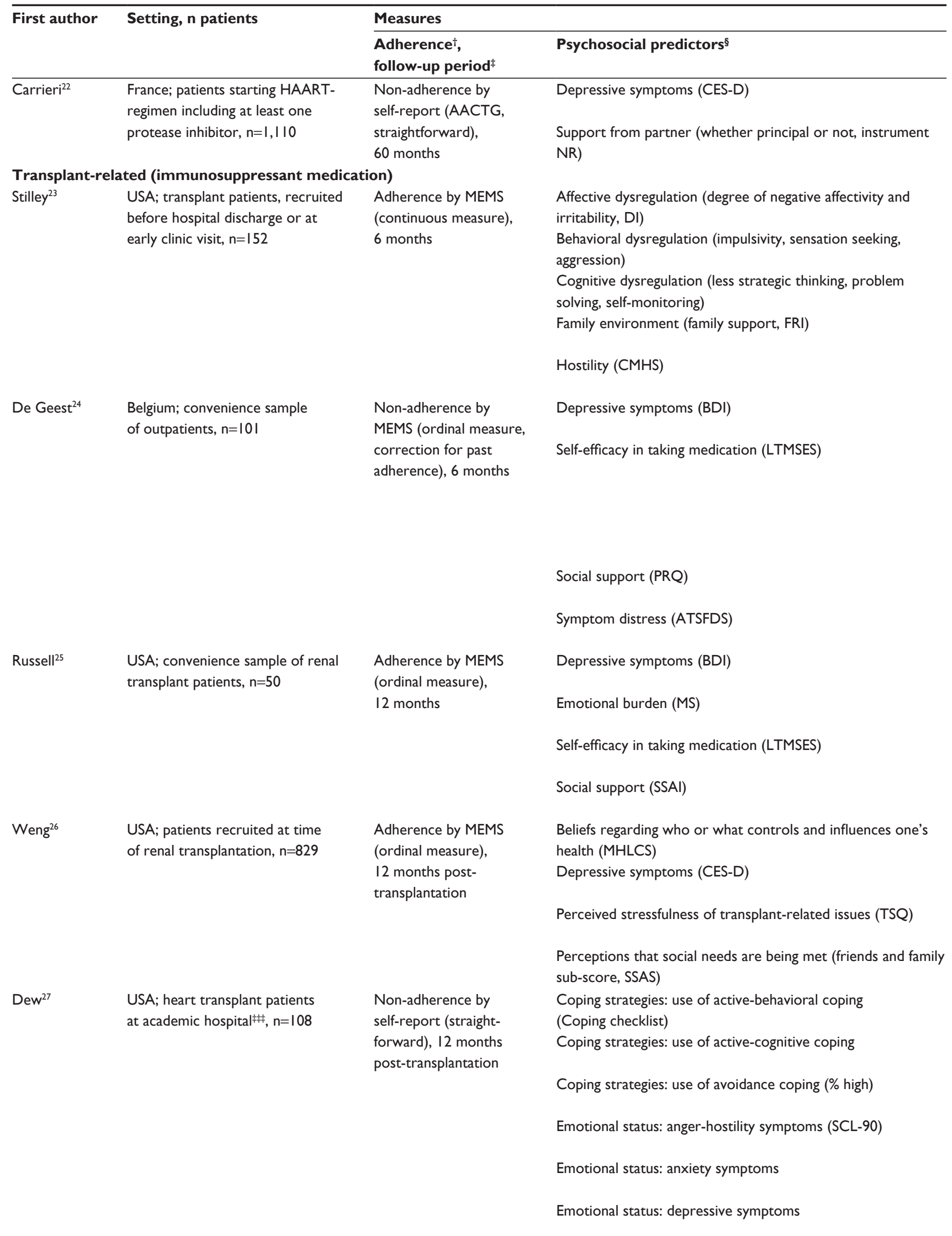




\begin{tabular}{|c|c|c|c|c|}
\hline \multirow[t]{2}{*}{ Psychcat"l } & \multicolumn{2}{|l|}{ Results" } & \multirow{2}{*}{$\begin{array}{l}\text { Direction of association } \\
\text { (regarding adherence)** }\end{array}$} & \multirow{2}{*}{$\begin{array}{l}\text { N domains } \\
\text { bias free }^{t t}\end{array}$} \\
\hline & Univariate & Multivariate & & \\
\hline \multirow[t]{2}{*}{ El } & $\mathrm{b}=0.22(95 \% \mathrm{Cl}=0.12,0.32), P<0.00 \mathrm{I}$ & $\mathrm{b}=0.18(0.07,0.29)$ & U: - & 2 of 6 \\
\hline & & & M: - & \\
\hline \multirow[t]{2}{*}{$\mathrm{Cll}$} & $b=-0.16(-0.26,-0.07), P=0.001$ & $\mathrm{~b}=-0.15(-0.25,-0.05)$ & $\mathrm{U:}+$ & \\
\hline & & & M: + & \\
\hline \multirow[t]{2}{*}{$\mathrm{El}$} & Correlation coefficient: NSTा & NR & U: 0 & I of 6 \\
\hline & & & M: NR & \\
\hline \multirow[t]{2}{*}{ D } & $r=0.26, P \leq 0.05^{* * *}$ & & U: $-{ }^{t+t}$ & \\
\hline & & & $M: N R$ & \\
\hline \multirow[t]{2}{*}{$\mathrm{BI}$} & NS & & $\mathrm{U:} 0$ & \\
\hline & & & $M: N R$ & \\
\hline \multirow[t]{2}{*}{$\mathrm{Cll}$} & NSTा & & U: 0 & \\
\hline & & & M: NR & \\
\hline \multirow[t]{2}{*}{ D } & NS & & $\mathrm{U}: 0$ & \\
\hline & & & $M: N R$ & \\
\hline \multirow[t]{2}{*}{ El } & NR & NS & U: NR & 2 of 6 \\
\hline & & & M: 0 & \\
\hline \multirow[t]{6}{*}{ Alll } & & Median $=4.85(\mathrm{Q} I=4.70$ & U: NR & \\
\hline & & $\mathrm{Q} 3=5.00)$ for excellent adherers, & $M:+$ & \\
\hline & & $4.8 \mathrm{I}(\mathrm{Q} \mathrm{I}=4.70, \mathrm{Q} 3=4.89) \mathrm{for}$ & & \\
\hline & & moderate non-adherers, & & \\
\hline & & $4.4 \mathrm{I}(\mathrm{QI}=4.30, \mathrm{Q} 3=4.8 \mathrm{I})$ for & & \\
\hline & & minor adherers, $P=0.04$ & & \\
\hline \multirow[t]{2}{*}{ CIII } & & NS & U: NR & \\
\hline & & & M: 0 & \\
\hline \multirow[t]{2}{*}{ Ell } & & NS & U: NR & \\
\hline & & & M: 0 & \\
\hline \multirow[t]{2}{*}{$\mathrm{El}$} & NS & NR & $\mathrm{U}: 0$ & 0 of 6 \\
\hline & & & M: NR & \\
\hline \multirow[t]{2}{*}{ El } & NS & & U: 0 & \\
\hline & & & M: NR & \\
\hline \multirow[t]{2}{*}{ Alll } & NS & & $\mathrm{U}: 0$ & \\
\hline & & & $M: N R$ & \\
\hline \multirow[t]{2}{*}{ CIII } & NS & & U: 0 & \\
\hline & & & $M: N R$ & \\
\hline Alll & $O R=1.05(I .00, I . I I), P=0.05$ (powerful others & NS & $\mathrm{U:}+$ & 2 of 6 \\
\hline & subscale) & & M: 0 & \\
\hline El & NS & NT & $\mathrm{U:} 0$ & \\
\hline & & & M: NT & \\
\hline Ell & NS & NT & $\mathrm{U}: 0$ & \\
\hline & & & M: NT & \\
\hline $\mathrm{Cll}$ & NS & NT & $\mathrm{U:} 0$ & \\
\hline & & & M: NT & \\
\hline $\mathrm{BI}$ & NS & NT & U: 0 & 2 of 6 \\
\hline & & & M: NT & \\
\hline $\mathrm{BI}$ & NS & NT & $\mathrm{U}: 0$ & \\
\hline & & & M: NT & \\
\hline BII & Non-adherent $58.8 \%$, adherent $29.9 \%, P<0.05$ & $\mathrm{OR}=9.7 \mathrm{I}, P<0.05$ & U: - & \\
\hline & & & M: - & \\
\hline El & Non-adherent $47.1 \%$, adherent $12.1 \%, P<0.00 \mid$ & $\mathrm{OR}=13.40, P<0.05$ & $\mathrm{U:}-$ & \\
\hline & & & M: - & \\
\hline El & Non-adherent $82.4 \%$, adherent $53 \%, P<0.05$ & NS & $\mathrm{U:}-$ & \\
\hline & & & M: 0 & \\
\hline El & NS & NT & $\mathrm{U}: 0$ & \\
\hline & & & M: NT & \\
\hline
\end{tabular}


Table S2 (Continued)

\begin{tabular}{|c|c|c|c|}
\hline \multirow[t]{2}{*}{ First author } & \multirow[t]{2}{*}{ Setting, n patients } & \multicolumn{2}{|l|}{ Measures } \\
\hline & & $\begin{array}{l}\text { Adherence }{ }^{\dagger} \\
\text { follow-up period } \ddagger\end{array}$ & Psychosocial predictors ${ }^{\S}$ \\
\hline & & & Sense of mastery (ie, control over life, SMS) \\
\hline & & & $\begin{array}{l}\text { Social support: caregiver support (\% poor) (Spanier, }{ }^{35} \text { Pearlin } \\
\text { and Schooler) }{ }^{36}\end{array}$ \\
\hline & & & Social support: friend support (Moos) ${ }^{37}$ \\
\hline \multirow[t]{7}{*}{ Dew $^{28}$} & $\begin{array}{l}\text { USA; patients receiving first lung } \\
\text { transplantation in academic hospital, } \\
n=178\end{array}$ & $\begin{array}{l}\text { Non-adherence by self- } \\
\text { report (straightforward), } \\
24 \text { months }\end{array}$ & $\begin{array}{l}\text { Anger-hostility symptoms (SC) } \\
\text { Anxiety symptoms (SC) }\end{array}$ \\
\hline & & & $\begin{array}{l}\text { Care provider locus of control (health outcomes due to } \\
\text { professional? MHLCS) }\end{array}$ \\
\hline & & & $\begin{array}{l}\text { Chance locus of control (health outcomes occur by } \\
\text { chance?) }\end{array}$ \\
\hline & & & $\begin{array}{l}\text { Degree to which one can rely on friends for emotional/ } \\
\text { practical support/friend support (Moos) } \\
\text { Depressive symptoms (SC) }\end{array}$ \\
\hline & & & Expectations about the future/optimism (LOT) \\
\hline & & & $\begin{array}{l}\text { Internal locus of control (can I influence my health outcome? } \\
\text { MHLCS) }\end{array}$ \\
\hline & & & $\begin{array}{l}\text { Supportiveness (both emotionally and practically) of } \\
\text { recipient's relationship with their primary family caregiver } \\
\text { (when low }=\text { higher odds) (DAS) }\end{array}$ \\
\hline \multirow[t]{8}{*}{ Dobbels $^{29}$} & $\begin{array}{l}\text { Belgium: heart, liver and lung } \\
\text { transplant patients listed at } \\
\text { university hospitals, } \mathrm{n}=186\end{array}$ & $\begin{array}{l}\text { Non-adherence by self- } \\
\text { report (straightforward, } \\
\text { corrected for pre- } \\
\text { transplant adherence), }\end{array}$ & $\begin{array}{l}\text { Agreeableness (one's orientation along continuum from } \\
\text { compassion to antagonism, NEO-FFI) } \\
\text { Anxiety symptoms (HADS) }\end{array}$ \\
\hline & & $\begin{array}{l}12 \text { months post- } \\
\text { transplantation }\end{array}$ & Conscientiousness (ie, degree of organization, NEO-FFI) \\
\hline & & & Depressive symptoms (HADS) \\
\hline & & & $\begin{array}{l}\text { Extraversion (capacity for joy, need for stimulation, } \\
\text { NEO-FFI) }\end{array}$ \\
\hline & & & General received practical and informational support (SSQ) \\
\hline & & & Neuroticism (NEO-FFI) \\
\hline & & & $\begin{array}{l}\text { Openness to experience (toleration for and exploration of the } \\
\text { unfamiliar, NEO-FFI) }\end{array}$ \\
\hline & & & Received specific support with medication taking (SSQ) \\
\hline
\end{tabular}




\begin{tabular}{|c|c|c|c|c|}
\hline \multirow[t]{2}{*}{ Psychcat"l } & \multicolumn{2}{|l|}{ Results" } & \multirow{2}{*}{$\begin{array}{l}\text { Direction of association } \\
\text { (regarding adherence)** }\end{array}$} & \multirow{2}{*}{$\begin{array}{l}\text { N domains } \\
\text { bias free }^{t \dagger}\end{array}$} \\
\hline & Univariate & Multivariate & & \\
\hline & & & U: 0 & \\
\hline \multirow[t]{2}{*}{ Alll } & NS & NT & M: NT & \\
\hline & & & $\mathrm{U:}-$ & \\
\hline \multirow[t]{2}{*}{ Cll } & Non-adherent $52.9 \%$, adherent $27.0 \%, P<0.05$ & NS & M: 0 & \\
\hline & & & U: 0 & \\
\hline Cll & NS & NT & M: NT & \\
\hline \multirow[t]{2}{*}{ El } & (Correlation coefficient, significant if & NS & U: ? & I of 6 \\
\hline & $\left.r \geq 0.15^{* * *}\right): r \geq 0.15$ & & M: 0 & \\
\hline \multirow[t]{2}{*}{$\mathrm{EI}$} & $r \geq 0.15$ & NS & U: ? & \\
\hline & & & M: 0 & \\
\hline \multirow[t]{2}{*}{ Alll } & $r \geq 0.15$ & NS & U: ? & \\
\hline & & & M: 0 & \\
\hline \multirow[t]{2}{*}{ Alll } & $r \geq 0.15$ & NS & $\mathrm{U}: ?$ & \\
\hline & & & M: 0 & \\
\hline \multirow[t]{2}{*}{$\mathrm{Cll}$} & $r \geq 0.15$ & NS & U: ? & \\
\hline & & & M: 0 & \\
\hline \multirow[t]{2}{*}{$\mathrm{EI}$} & $r \geq 0.15$ & NS & U: ? & \\
\hline & & & M: 0 & \\
\hline \multirow[t]{2}{*}{$\mathrm{D}$} & $r \geq 0.15$ & NS & U: ? & \\
\hline & & & M: 0 & \\
\hline \multirow[t]{2}{*}{ Alll } & $r \geq 0.15$ & NS & U: ? & \\
\hline & & & M: 0 & \\
\hline \multirow[t]{2}{*}{$\mathrm{Cll}$} & $r \geq 0.15$ & $\mathrm{OR}=2.59(\mathrm{I} .20,5.58), P<0.05$ & U: ? & \\
\hline & & & M: - & \\
\hline \multirow[t]{2}{*}{$D$} & NR & NT or NS & U: NR/NS & 1 of 6 \\
\hline & & & M: 0 & \\
\hline \multirow[t]{2}{*}{ El } & & NT or NS & U: NR/NS & \\
\hline & & & M: 0 & \\
\hline \multirow[t]{2}{*}{$D$} & & $\mathrm{OR}=0.80(0.67,0.95), P=0.0 \mathrm{I}$ & U: NR/NS & \\
\hline & & & $M:+$ & \\
\hline \multirow[t]{2}{*}{ EI } & & NT or NS & U: NR/NS & \\
\hline & & & M: 0 & \\
\hline \multirow[t]{2}{*}{$D$} & & NT or NS & U: NR/NS & \\
\hline & & & M: 0 & \\
\hline \multirow[t]{2}{*}{ CIII } & & NT or NS & U: NR/NS & \\
\hline & & & M: 0 & \\
\hline \multirow[t]{2}{*}{$D$} & & NT or NS & U: NR/NS & \\
\hline & & & M: 0 & \\
\hline \multirow[t]{2}{*}{ D } & & NT or NS & U: NR/NS & \\
\hline & & & M: 0 & \\
\hline \multirow[t]{2}{*}{ CIII } & & $\mathrm{OR}=0.94(0.89,0.99), P=0.03$ & U: NR/NS & \\
\hline & & & $M:+$ & \\
\hline
\end{tabular}


Table S2 (Continued)

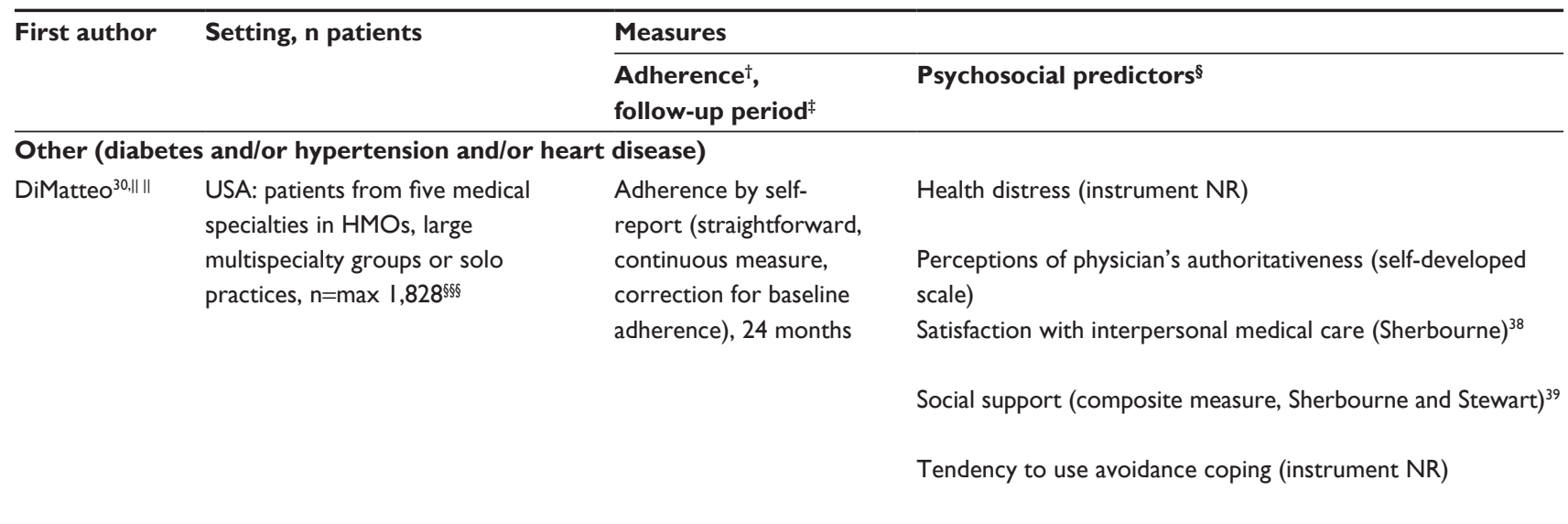

Notes: *NS (non significant): as reported in the concerning study. UD (undetermined): because of inadequate description in the concerning study. 'Binary outcome measure, unless indicated otherwise.

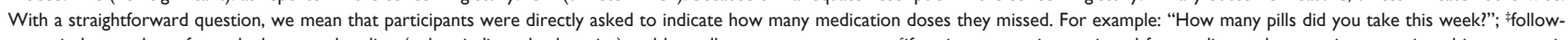

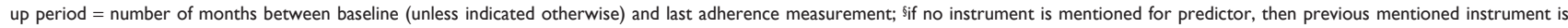
applicable; "psychosocial category, to which a predictor was assigned. A = Beliefs and cognitions about: I) medication and treatment; II) illness; III) self-efficacy and locus of control. B = coping styles: I) task oriented, II) emotion oriented. C = Social influences and social support: I) regarding medical caregiver; II) regarding friends and family; III) in general. D = personality traits. $E=$ psychological wellbeing: I) mood state; II) perceived stress/stressors; "IOR: Odds Ratio ( $95 \%$ confidence interval). OR $<$ I = lower chance of being adherent or non-adherent (for direction in relevant study, see column "Adherence, follow-up period") when predictor increases or when predictor $\neq$ reference category. OR $>I=$ greater change of being adherent or non-adherent when predictor increases (or when predictor $\neq$ reference category). Scores other than OR are the mean predictor scores with standard deviation, unless indicated otherwise; $* *_{+}=$higher level of predictor implies higher adherence at level $P \leq 0.05 ;-=$ higher level of predictor implies less adherence at $P \leq 0.05 ; 0=$ no significant association between predictor and adherence at $P \leq 0.05 ; ?=$ association present, but direction unclear; $+\dagger$ to determine methodological quality, six bias domains per study were judged. Here, the total amount of bias free domains is reported (for further details, see table S3); \#assumed that all variables, tested by univariate analysis, were also tested by multivariate analysis; ${ }^{56}$ retrospective design; II "Diagnosis for coronary heart disease, hypertension, diabetes mellitus and/or hyperlipidaemia; 11 not reported in study is interpreted by $\mathrm{HZ} / \mathrm{BvdB}$ as not significant; ***significance of $P \leq 0.05$ assumed by $\mathrm{HZ} / \mathrm{BvdB}$; ${ }^{+t}$ negative association assumed; \#\#type of medication is immunosuppressants, antihypertensives, and/ or antivirals; $\$ \$ \$$ use of chronic preventive medication assumed; II II lunexpected direction.

Abbreviations: AACTG, adult AIDS clinical trials group; ALTMBSES, adapted long term medication behavior self efficacy scale; AGSRP, adapted gay service research project; AIDS, acquired immunodeficiency syndrome; AMHI, adapted mental health inventory; APIAQ, adapted protease inhibitor attitude questionnaire; ART, antiretroviral therapy; ASBSI, anxiety subscale of brief symptom inventory; ATS, anxiety trait scale; ATSFDS, adapted version of transplant symptom frequency and distress scale; AWC, adapted ways of coping; BDI, beck depression inventory; BHLES, buffalo HIV life events survey; BHS, beck hopelessness scale; BMICIS, Billings and Moos inventory of coping with illness styles; BMQ, beliefs about medication questionnaire; BST, Burnam interviewer-administered 8-item screening tool; CES-D, center for epidemiologic studies depression scale; CMHS, Cook-Medley hostility scale; DAS, dyadic adjustment scale; DI, dysregulation inventory; DOS, dispositional optimism scale; DSBSI, depression subscale of brief symptom inventory; DSPERI, demoralization scale of psychiatric epidemiology research interview; FRI, family relations index (from family environment scale); FTSSH, Finnish twin study scale of hostility; GHQ, general health questionnaire; HAART, highly active antiretroviral therapy; HADS, hospital anxiety and depression scale; HAT-QOL, HIV/AIDS-targeted quality of life instrument; HBS, health behaviour scale; HCSUS, HIV cost and services utilization study; HIE, Horowitz impact of events scale; HIS, health intention scale; HIV, human immunodeficiency virus; HMO, health maintenance organization; ICS, inhaled corticosteroids; IDD, inventory to diagnose depression; IQR, interquartile range; ISEL, interpersonal support evaluation list; LES, life experience survey; LOT-R, life orientation test; LSS, life stressors scale; LTMSES, long term medication self-efficacy scale; MAH, mental adjustment to HIV; MARS, medication adherence report scale; MAS, Miller attitude scale; MASRI, medication adherence self-report inventory; MEMS, medication even monitoring system; MHLCS, multidimensional health locus of control scale; MOS, medical outcome study health survey; MS, Memphis survey; NEO-FFI, NEO five factor inventory; NR, not reported; NS, non-significant; NSEPQSS, neuroticism scale of the Eysenck personality questionnaire-revised short scale; NT, not tested; OR, odds ratio; Pat SS, patient satisfaction scale; PEI, psychiatric epidemiology interview; POMS, profiles of mood states; PPCS, perceived parenting competence scale; PRQ, personal resource questionnaire; PSS, perceived stress scale; RSEQR, Rosenberg self-esteem questionnaire; SC, symptom checklist; SCL-90, Symptom Checklist-90-R; SEM, standard error of the mean; SF-36, short form-36 health survey; SMS, sense of mastery scale; SOC, sense of coherence; SPS, social provision scale; SSAI, social support appraisals index; SSAS, social support appraisal scale; SSQ, social support questionnaire; TSQ, transplant stress questionnaire; VAS, visual analog scale. 


\begin{tabular}{|c|c|c|c|c|}
\hline \multirow[t]{2}{*}{ Psychcat" } & \multicolumn{2}{|l|}{ Results $\pi$} & \multirow{2}{*}{$\begin{array}{l}\text { Direction of association } \\
\text { (regarding adherence)** }^{* *}\end{array}$} & \multirow{2}{*}{$\begin{array}{l}\text { N domains } \\
\text { bias free }^{t t}\end{array}$} \\
\hline & Univariate & Multivariate & & \\
\hline \multirow[t]{2}{*}{ Ell } & NR & $\beta=-0.22, P=0.05$ & U: NR & 0 of 6 \\
\hline & & & M: - & \\
\hline \multirow[t]{2}{*}{$\mathrm{Cl}$} & & NT or NS & $U: N R$ & \\
\hline & & & M: 0 & \\
\hline \multirow[t]{2}{*}{$\mathrm{Cl}$} & & NT or NS & U: NR & \\
\hline & & & M: 0 & \\
\hline \multirow[t]{2}{*}{ CIII } & & NT or NS & U: NR & \\
\hline & & & M: 0 & \\
\hline \multirow[t]{2}{*}{ BII } & & NT or NS & U: NR & \\
\hline & & & M: 0 & \\
\hline
\end{tabular}


Table S3 Results of judging methodologic quality

\begin{tabular}{|c|c|c|c|c|c|c|c|}
\hline \multirow[t]{2}{*}{ First author } & \multirow{2}{*}{$\begin{array}{l}\text { Overall } \\
\text { quality }\end{array}$} & \multicolumn{6}{|c|}{ Domain free of bias? } \\
\hline & & $\begin{array}{l}\text { Study } \\
\text { participation }\end{array}$ & $\begin{array}{l}\text { Study } \\
\text { attrition }\end{array}$ & $\begin{array}{l}\text { Prognostic factor } \\
\text { measurement }\end{array}$ & $\begin{array}{l}\text { Outcome } \\
\text { measurement }\end{array}$ & $\begin{array}{l}\text { Confounding measurement } \\
\text { and account }\end{array}$ & Analysis \\
\hline Bottonari ${ }^{13}$ & Low & No & No & Partly & Partly & No & No \\
\hline De Geest ${ }^{24}$ & Low & No & Yes & Partly & Yes & No & Partly \\
\hline Delgado $^{10}$ & Low & Partly & Yes & Partly & Partly & Partly & Partly \\
\hline Deschamps $^{8}$ & Low & No & Partly & No & Yes & No & No \\
\hline $\mathrm{Dew}^{27}$ & Low & No & Yes & Yes & Partly & Partly & Partly \\
\hline $\operatorname{Dew}^{28}$ & Low & Yes & Partly & Partly & Partly & Partly & Partly \\
\hline DiMatteo $^{30}$ & Low & Partly & No & Partly & No & No & No \\
\hline Dobbels $^{29}$ & Low & Yes & Partly & Partly & Partly & Partly & No \\
\hline Gazmararian $^{3}$ & Low & Yes & Partly & Partly & Yes & Partly & Yes \\
\hline Godin ${ }^{14}$ & Low & Partly & Yes & No & Partly & Partly & Partly \\
\hline Grégoire $^{5}$ & Low & Partly & No & No & Partly & No & Partly \\
\hline Holmes 9 & Low & Partly & Yes & Partly & Partly & Partly & Yes \\
\hline Kacanek $^{15}$ & Low & No & Yes & Partly & Partly & No & Yes \\
\hline Martini' ${ }^{16}$ & Low & Partly & No & No & Partly & No & No \\
\hline Mellins ${ }^{17}$ & Low & Partly & Partly & Partly & No & No & No \\
\hline Miller ${ }^{6}$ & Low & No & Partly & Partly & No & Partly & Partly \\
\hline $\mathrm{Nabi}^{4}$ & Low & Partly & Partly & Partly & Partly & Partly & Yes \\
\hline Nilsson & Low & Partly & Yes & Partly & No & Partly & No \\
\hline \multicolumn{8}{|l|}{ Schönnesson ${ }^{18}$} \\
\hline Ponieman' & Low & No & No & Partly & Partly & Partly & Partly \\
\hline Russell ${ }^{25}$ & Low & No & No & Partly & Partly & No & Partly \\
\hline Singh"' & Low & No & Yes & Partly & Partly & Partly & No \\
\hline Singh 12 & Low & Partly & Yes & Partly & Partly & No & No \\
\hline Stilley ${ }^{23}$ & Low & Yes & Partly & Partly & No & No & No \\
\hline Thrasher ${ }^{19}$ & Low & Yes & Partly & Partly & Partly & Partly & Partly \\
\hline Venturini ${ }^{2}$ & Low & Yes & Partly & Partly & Yes & Partly & Partly \\
\hline Weng ${ }^{26}$ & Low & Partly & No & Yes & Partly & Partly & Yes \\
\hline Molloy ${ }^{7}$ & Low & No & Yes & Partly & No & Partly & Partly \\
\hline Horne 20 & Low & Yes & Yes & Partly & Partly & No & Yes \\
\hline Mugavero ${ }^{21}$ & Low & Yes & No & Yes & Partly & Partly & Yes \\
\hline Carrierii $^{22}$ & Low & No & Yes & No & Partly & Partly & Yes \\
\hline
\end{tabular}




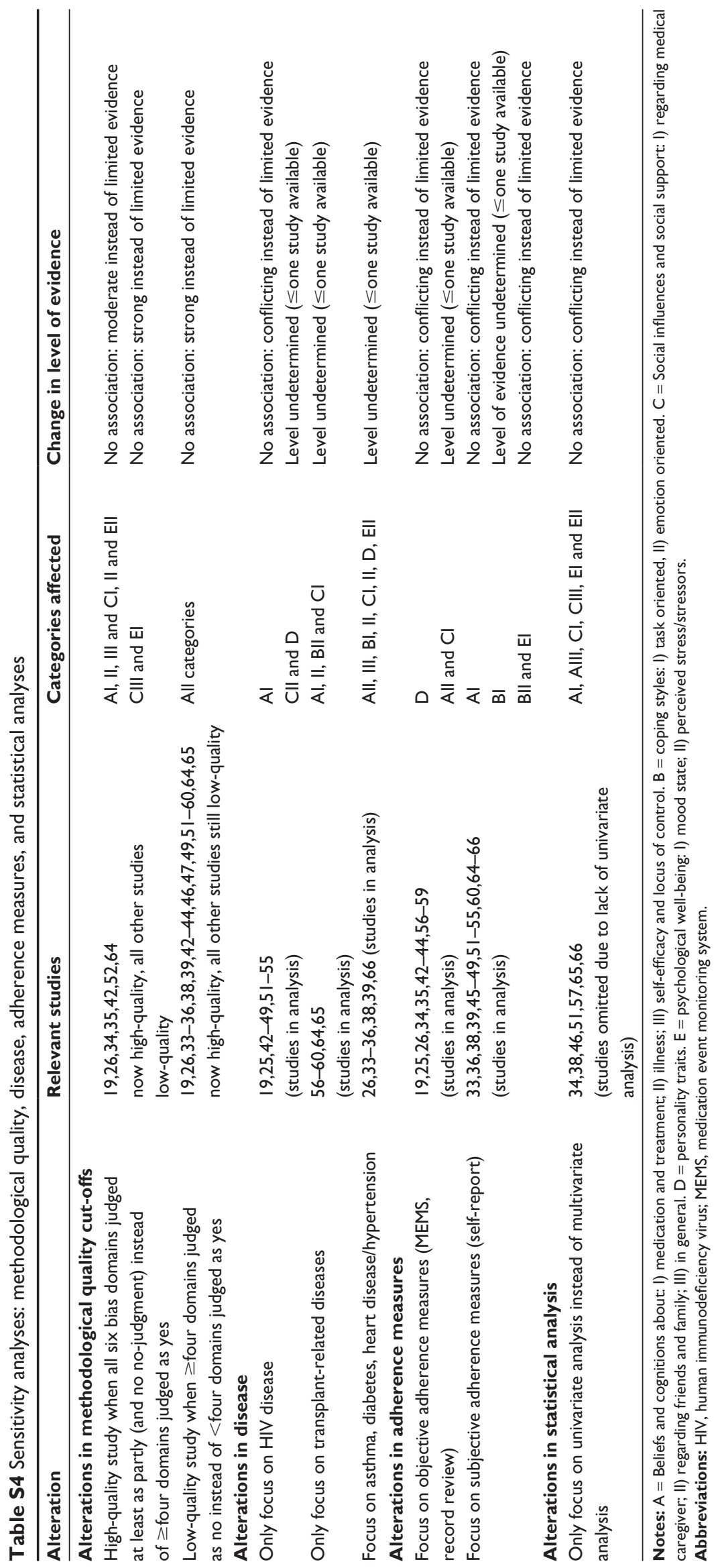




\section{References}

1. Ponieman D, Wisnivesky JP, Leventhal H, Musumeci-Szabó TJ, Halm EA. Impact of positive and negative beliefs about inhaled corticosteroids on adherence in inner-city asthmatic patients. Ann Allergy Asthma Immunol. 2009;103(1):38-42.

2. Venturini F, Nichol MB, Sung JC, Bailey KL, Cody M, McCombs JS. Compliance with sulfonylureas in a health maintenance organization: a pharmacy record-based study. Ann Pharmacother. 1999;33(3): 281-288.

3. Gazmararian JA, Kripalani S, Miller MJ, Echt KV, Ren J, Rask K. Factors associated with medication refill adherence in cardiovascularrelated diseases: a focus on health literacy. J Gen Intern Med. 2006; 21(12):1215-1221.

4. Nabi H, Vahtera J, Singh-Manoux A, et al. Do psychological attributes matter for adherence to antihypertensive medication? The Finnish Public Sector Cohort Study. J Hypertens. 2008;26(11):2236-2243.

5. Grégoire J, Moisan J, Guibert R, Ciampi A, Milot A. Predictors of self-reported noncompliance with antihypertensive drug treatment: a prospective cohort study. Can J Cardiol. 2006;22(4):323-329.

6. Miller P, Wikoff RL, McMahon M, Garrett MJ, Ringel K. Indicators of medical regimen adherence for myocardial infarction patients. Nurs Res. 1985;34(5):268-272.

7. Molloy GJ, Perkins-Porras L, Bhattacharyya MR, Strike PC, Steptoe A. Practical support predicts medication adherence and attendance at cardiac rehabilitation following acute coronary syndrome. J Psychosom Res. 2008;65(6):581-586.

8. Deschamps AE, Graeve VD, van Wijngaerden E, et al. Prevalence and correlates of nonadherence to antiretroviral therapy in a population of HIV patients using Medication Event Monitoring System. AIDS Patient Care STDS. 2004;18(11):644-657.

9. Holmes WC, Bilker WB, Wang H, Chapman J, Gross R. HIV/AIDSspecific quality of life and adherence to antiretroviral therapy over time. J Acquir Immune Defic Syndr. 2007;46(3):323-327.

10. Delgado J, Heath KV, Yip B, et al. Highly active antiretroviral therapy: physician experience and enhanced adherence to prescription refill. Antivir Ther. 2003;8(5):471-478.

11. Singh N, Squier C, Sivek C, Wagener M, Nguyen MH, Yu VL. Determinants of compliance with antiretroviral therapy in patients with human immunodeficiency virus: prospective assessment with implications for enhancing compliance. AIDS Care. 1996;8(3):261-269.

12. Singh N, Berman SM, Swindells S, et al. Adherence of human immunodeficiency virus-infected patients to antiretroviral therapy. Clin Infect Dis. 1999;29(4):824-830.

13. Bottonari KA, Roberts JE, Ciesla JA, Hewitt RG. Life stress and adherence to antiretroviral therapy among HIV-positive individuals: a preliminary investigation. AIDS Patient Care STDS. 2005;19(11):719-727.

14. Godin G, Côté J, Naccache H, Lambert LD, Trottier S. Prediction of adherence to antiretroviral therapy: a one-year longitudinal study. AIDS Care. 2005;17(4):493-504.

15. Kacanek D, Jacobson DL, Spiegelman D, Wanke C, Isaac R, Wilson IB. Incident depression symptoms are associated with poorer HAART adherence: a longitudinal analysis from the Nutrition for Healthy Living study. J Acquir Immune Defic Syndr. 2010;53(2):266-272.

16. Martini M, D'Elia S, Paoletti F, et al. Adherence to HIV treatment: results from a 1-year follow-up study. HIV Med. 2002;3(1):62-64.

17. Mellins CA, Kang E, Leu CS, Havens JF, Chesney MA. Longitudinal study of mental health and psychosocial predictors of medical treatment adherence in mothers living with HIV disease.AIDS Patient Care STDS. 2003;17(8):407-416.

18. Nilsson Schönnesson L, Diamond PM, Ross MW, Williams M, Bratt G. Baseline predictors of three types of antiretroviral therapy (ART) adherence: A 2-year follow-up. AIDS Care. 2006;18(4):407-414.

19. Thrasher AD, Earp JA, Golin CE, Zimmer CR. Discrimination, distrust, and racial/ethnic disparities in antiretroviral therapy adherence among a national sample of HIV-infected patients. J Acquir Immune Defic Syndr. 2008;49(1):84-93.
20. Horne R, Cooper V, Gellaitry G, Date HL, Fisher M. Patients' perceptions of highly active antiretroviral therapy in relation to treatment uptake and adherence: the utility of the necessity-concerns framework. J Acquir Immune Defic Syndr. 2007;45(3):334-341.

21. Mugavero MJ, Raper JL, Reif S, et al. Overload: impact of incident stressful events on antiretroviral medication adherence and virologic failure in a longitudinal, multisite human immunodeficiency virus cohort study. Psychosom Med. 2009;71(9):920-926.

22. Carrieri MP, Leport C, Protopopescu C, et al. Factors associated with nonadherence to highly active antiretroviral therapy: a 5-year follow-up analysis with correction for the bias induced by missing data in the treatment maintenance phase. JAcquir Immune Defic Syndr. 2006;41(4):477-485.

23. Stilley CS, DiMartini AF, de Vera ME, et al. Individual and environmental correlates and predictors of early adherence and outcomes after liver transplantation. Prog Transplant. 2010;20(1):58-66; quiz 67.

24. De Geest S, Abraham I, Moons P, et al. Late acute rejection and subclinical noncompliance with cyclosporine therapy in heart transplant recipients. J Heart Lung Transplant. 1998;17(9):854-863.

25. Russell CL, Cetingok M, Hamburger KQ, et al. Medication adherence in older renal transplant recipients. Clin Nurs Res. 2010;19(2):95-112.

26. Weng FL, Israni AK, Joffe MM, et al. Race and electronically measured adherence to immunosuppressive medications after deceased donor renal transplantation. J Am Soc Nephrol. 2005;16(6):1839-1848.

27. Dew MA, Roth LH, Thompson ME, Kormos RL, Griffith BP. Medical compliance and its predictors in the first year after heart transplantation. J Heart Lung Transplant. 1996;15(6):631-645.

28. Dew MA, Dimartini AF, De Vito DabbsA, et al. Adherence to the medical regimen during the first two years after lung transplantation. Transplantation. 2008;85(2):193-202.

29. Dobbels F, Vanhaecke J, Dupont L, et al. Pretransplant predictors of posttransplant adherence and clinical outcome: an evidence base for pretransplant psychosocial screening. Transplantation. 2009; 87(10):1497-1504.

30. DiMatteo MR, Sherbourne CD, Hays RD, et al. Physicians' characteristics influence patients' adherence to medical treatment: results from the Medical Outcomes Study. Health Psychol. 1993;12(2):93-102.

31. Pearlin LI, Lieberman MA, Menaghan EG, Mullan JT. The stress process. J Health Soc Behav. 1981;22(4):337-356.

32. Berkman LF, Leo-Summers L, Horwitz RI. Emotional support and survival after myocardial infarction. A prospective, population-based study of the elderly. Ann Intern Med. 1992;117(12):1003-1009.

33. Seeman TE, Berkman LF. Structural characteristics of social networks and their relationship with social support in the elderly: who provides support. Soc Sci Med. 1988;26(7):737-749.

34. Chesney MA, Ickovics JR, Chambers DB, et al. Self-reported adherence to antiretroviral medications among participants in HIV clinical trials: the AACTG adherence instruments. Patient Care Committee and Adherence Working Group of the Outcomes Committee of the Adult AIDS Clinical Trials Group (AACTG). AIDS Care. 2000;12(3):255-266.

35. Spanier GB. Measuring dyadic adjustment: New scales for assessing the quality of marriage and similar dyads. J Marriage Fam. 1976;38(1):15-28.

36. Pearlin LI, Schooler C. The structure of coping. J Health Soc Behav. 1978;19(1):2-21.

37. Moos RH. Evaluating correctional and community settings. In: Ahmed I, Coelho GV, editors. Toward a New Definition of Health: Psychosocial Dimensions. New York: Plenum Press; 1979:337-360.

38. Sherbourne CD, Hays RD, Ordway L, DiMatteo MR, Kravitz RL. Antecedents of adherence to medical recommendations: results from the Medical Outcomes Study. J Behav Med. 1992;15(5):447-468.

39. Sherbourne CD, Stewart AL. The MOS social support survey. Soc Sci Med. 1991;32(6):705-714. 
Patient Preference and Adherence

Dovepress

\section{Publish your work in this journal}

Patient Preference and Adherence is an international, peer-reviewed, open access journal focusing on the growing importance of patient preference and adherence throughout the therapeutic continuum. Patient satisfaction, acceptability, quality of life, compliance, persistence and their role in developing new therapeutic modalities and compounds to optimize clinical outcomes for existing disease states are major areas of interest. This journal has been accepted for indexing on PubMed Central. The manuscript management system is completely online and includes a very quick and fair peer-review system. Visit http://www.dovepress.com/ testimonials.php to read real quotes from published authors.

Submit your manuscript here: http://www.dovepress.com/patient-preference-and-adherence-journal 